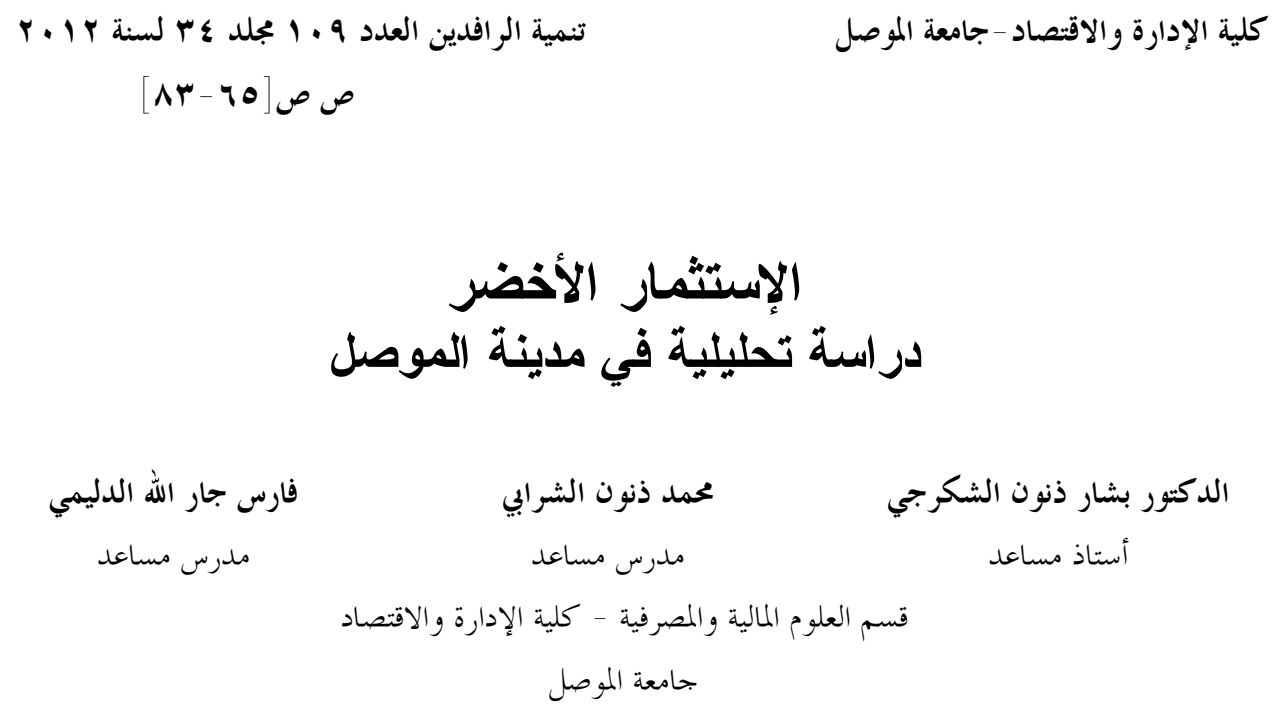

\begin{abstract}
المستخلص
إن مجرد وجود المدن المكتظة لا يعني تحضر اً و إنما ينبغي أن يكون هناتك توازنــاً بــين

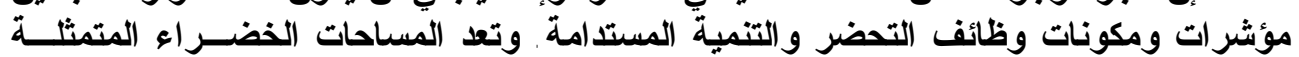

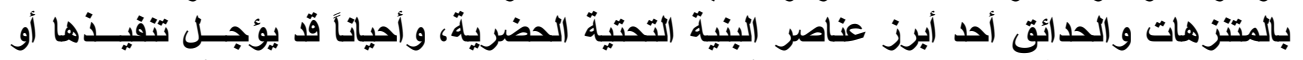

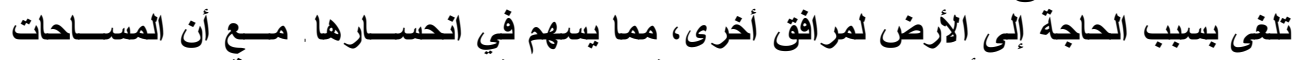

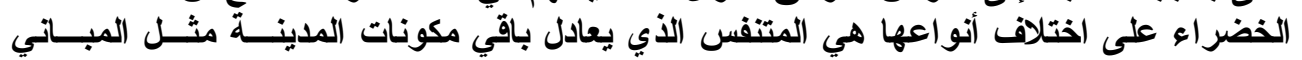

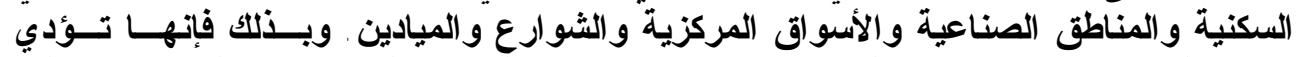

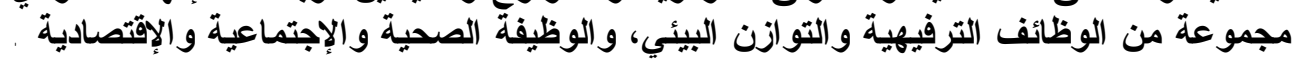

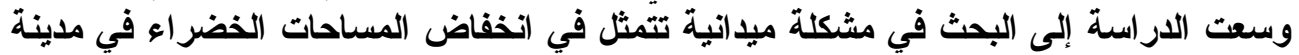

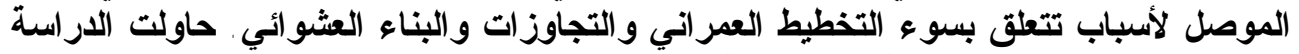

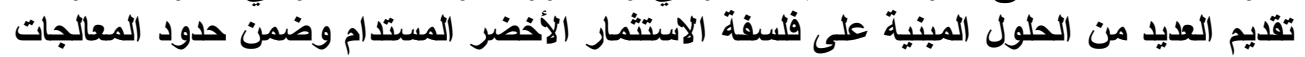

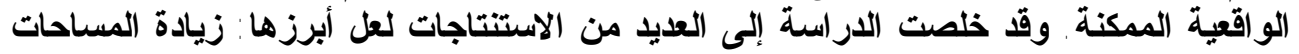

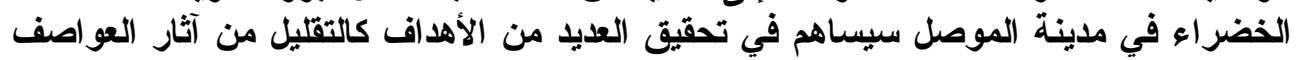

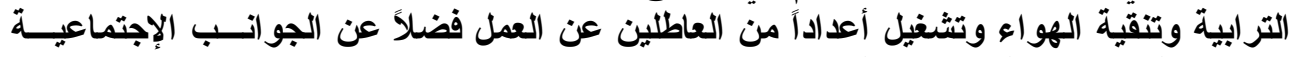
والمحافظة على البيئة المستدامة ولثئ.
\end{abstract}

المستدامة، الاستثمار ، الأخضر .

تأريخ قبول النشر 0 تأريخ استلام البحث ع |/ع/ | + r 


\title{
Green Investment: Analysis study in the City of Mosul
}

\author{
Bashar Th. Al-Shakerji (PhD) Mohammed Th. Al-Sharabi \\ Assistant Professor \\ Assistant Lecturer \\ Dept. of Financial and Banking Sciences \\ University of Mosul
}

\author{
Faris J. Al-Dulaimi \\ Assistant Lecturer
}

\begin{abstract}
The mere existence of crowded cities does not refer civilization, but there should be a balance between the indicators, components and functions of urbanization, as well as sustainable development. The green locations of parks and gardens are one of the most prominent elements of urban infrastructure. Sometimes the implementation may be delayed or canceled due to the need to spaces for other projects; this may contribute to the declination. The green location is the most comfortable that is equivalent to the rest of the components of the city. It contributes in many areas enabled the construction of residential and industrial areas, supermarkets, streets and squares. Thus, they play a set of functions such as recreational and ecological balance and function of health and socio-economic. The study sought to address the problem field that is the depletion of green areas in Mosul City, due to the poor planning, the physical abuse and arbitrary construction. The study tried to provide several solutions based on the philosophy of sustainable and green investment within the limits of realism possible treatments. The study concluded several results, they are; the increase of green location in the Mosul City will consequently contribute to the achievement of many goals such as decreasing the effects of sand storms, air filtration and run numbers of the unemployed, as well as social aspects and maintain a sustainable environment.
\end{abstract}

\section{Key wards:}

sustainable, investment, green .

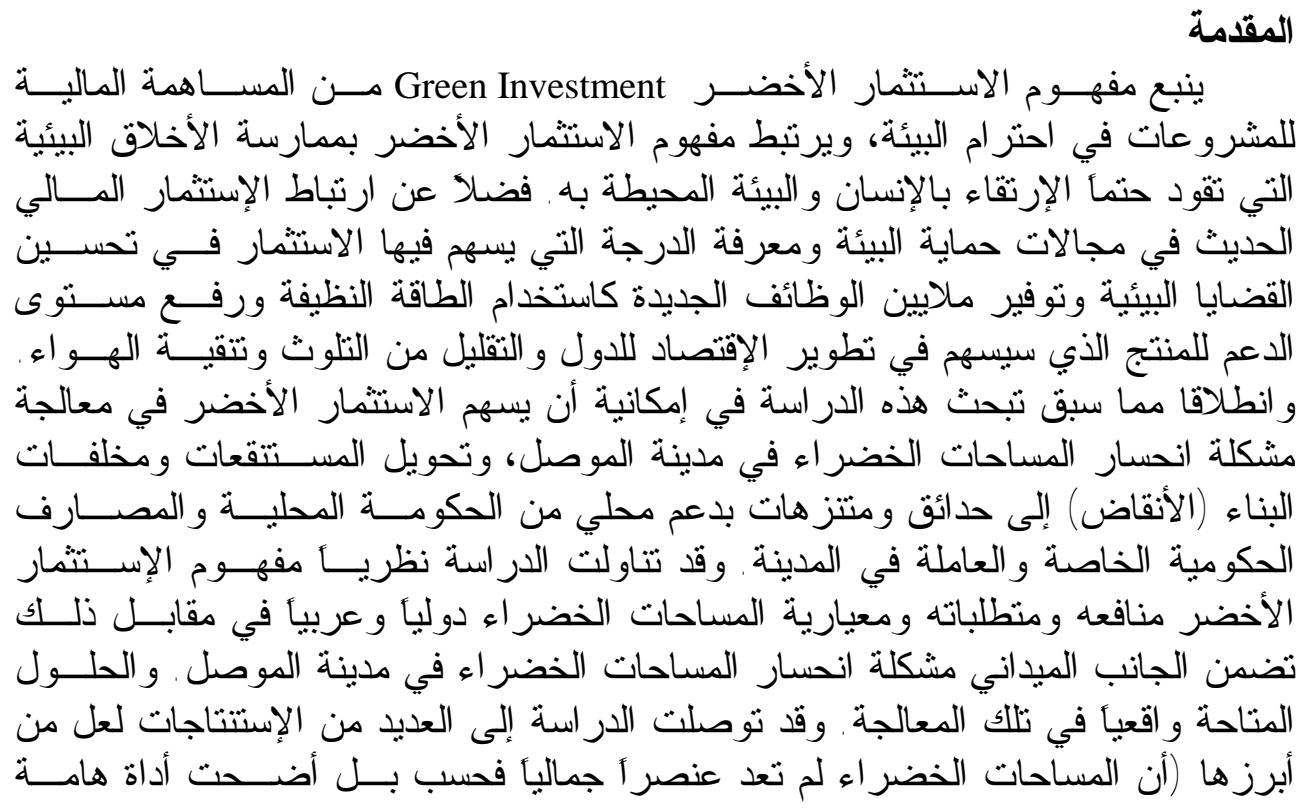




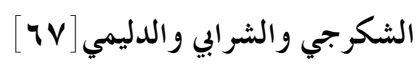

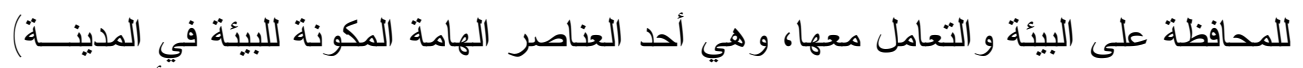

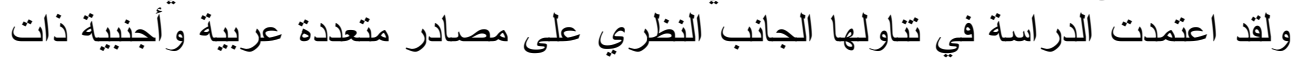

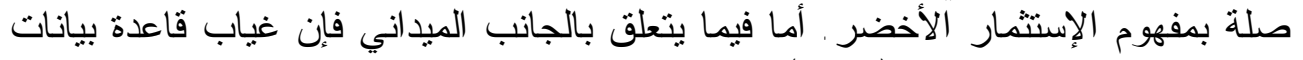

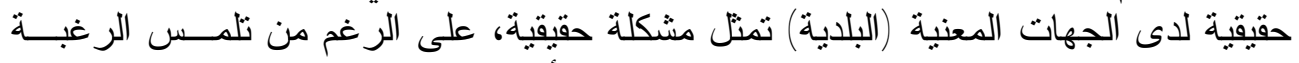

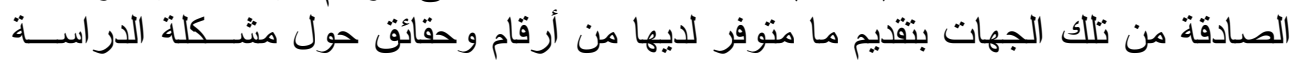
المتمنلة بانحسار المساحات الخضر اء في مدينة الموصل.

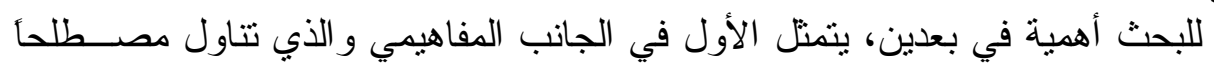
منهجية البحث

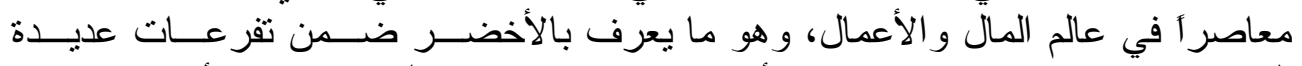

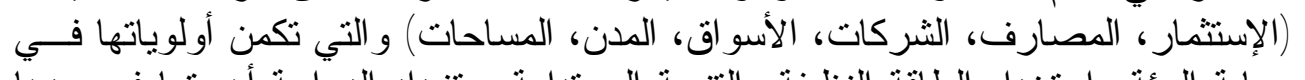

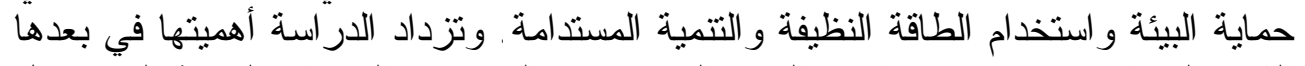

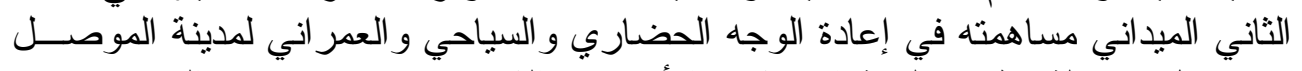

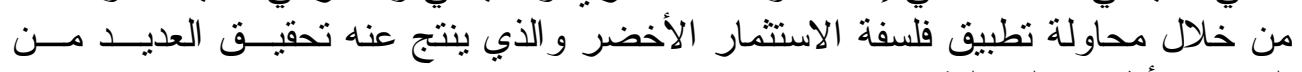
الفو ائد و لأطر افه المختلفة.

المشكلة

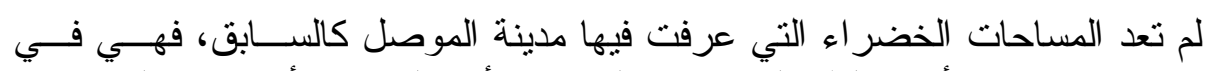

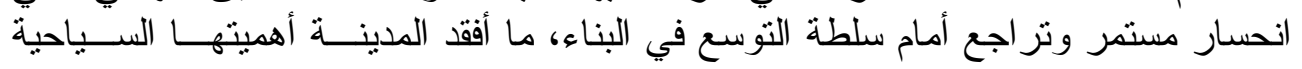

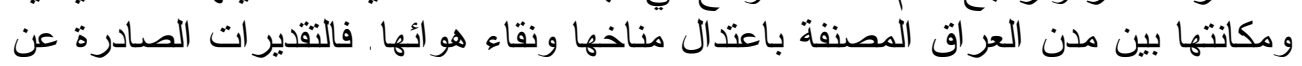

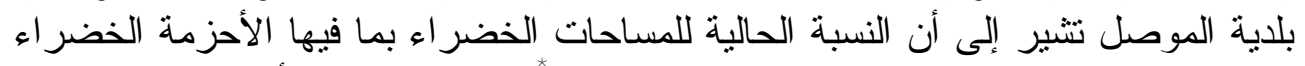

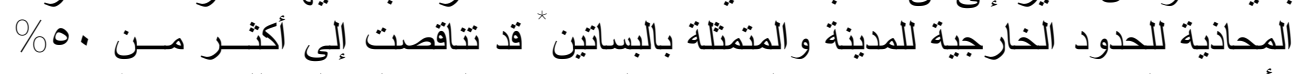

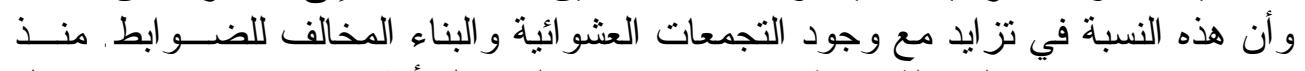

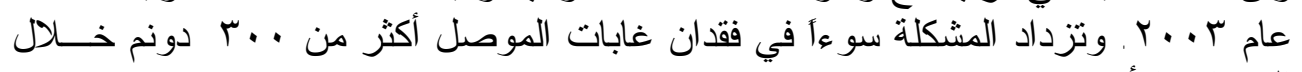

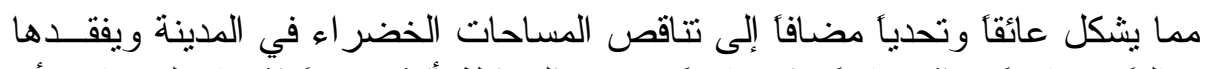

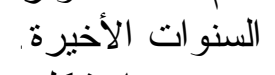

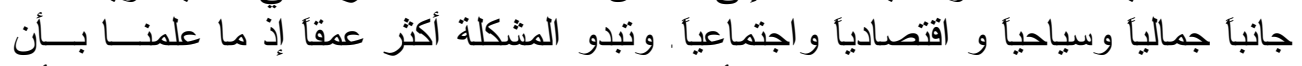

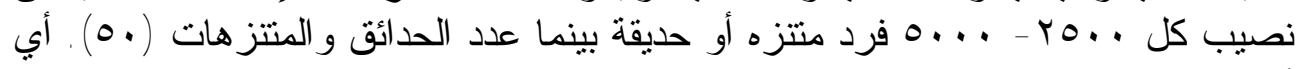

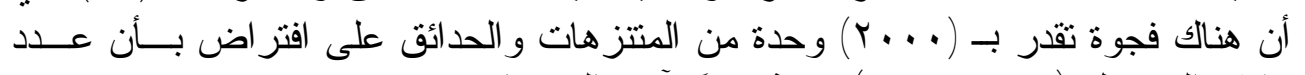

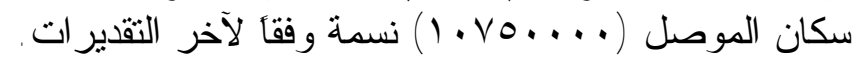

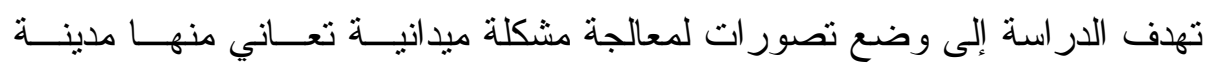

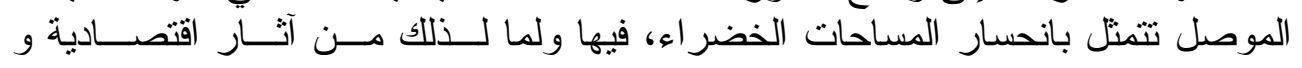
*كانت مدينة الموصل وحتى خمسينات القرن المنصرم تمنلاك أكثر من ع بـ بستانأ للفو اكه، أما اليوم فقــــ

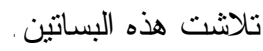


اجتماعية وبيئية و لأسباب تم تحديدها. ويشكل التأطير النظري لفلسفة الإستثمار الأخضــر

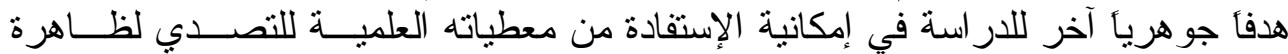

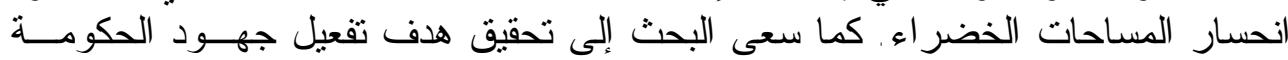
المحلية و المصارف العاملة في نطاق المدينة للمساهمة الجادة في تللك المعالجة عن طريق المريق ما يعرف بالقروض الخضر اءوفاء.

بناء على ما ورد في مشكلة الدر اسة يمكن صياغة الفرضية الآتية:

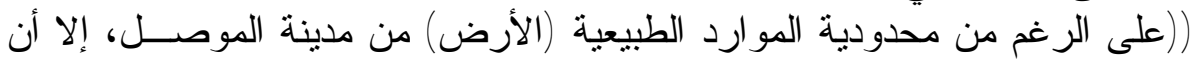
زيادة المساحات الخضر اء لاء لاز زالت قائمة)) .

\section{الحدود الزمانية و المكانية للار اسة}

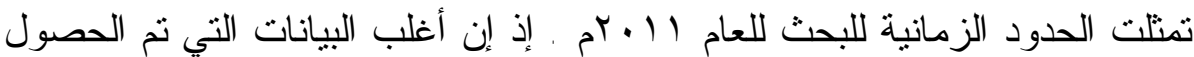

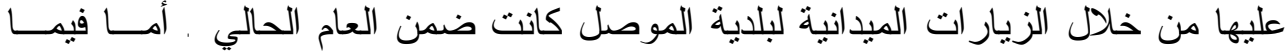

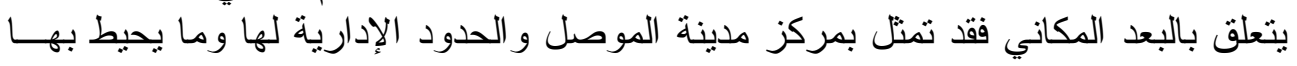
من الضواحي بالعد المكي

\section{مفهوم الإستثمار الأخضر ومتطلباته أولاً - مفهوم الإسئمار الأستثمار الأخضر}

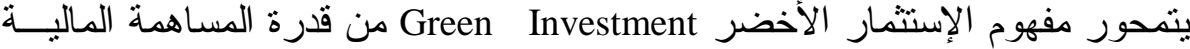

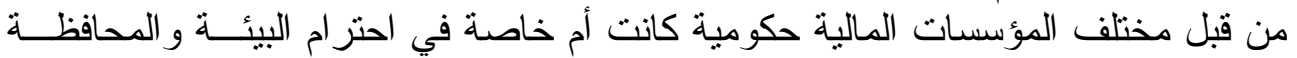

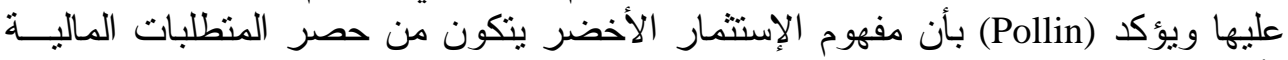

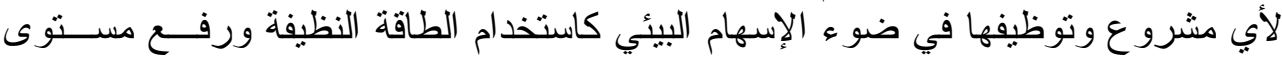

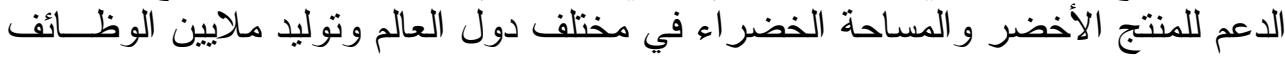

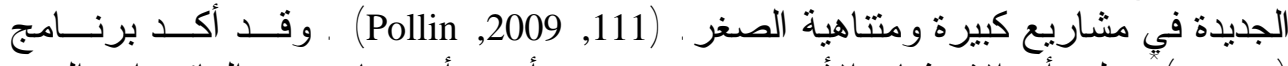
(UNEP)

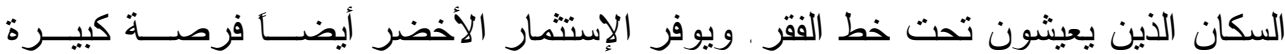

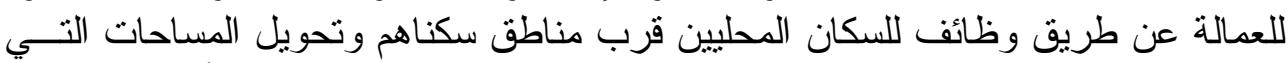

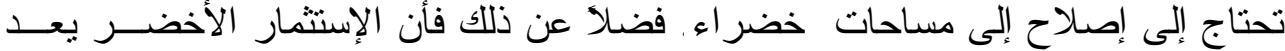

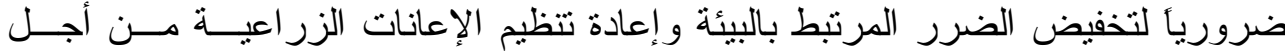

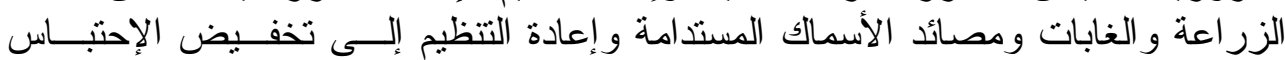

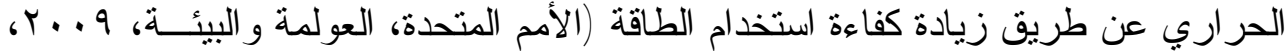

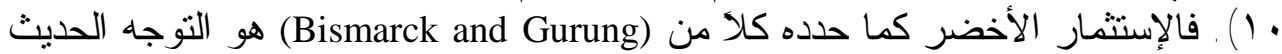

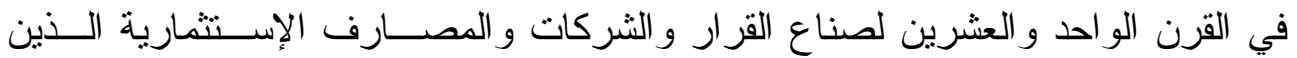
يتوسمون في عالم جديد أخضر لمو اجهة التحديات البيئية واستخدام تقنيات مبتكرة لإنتــاج

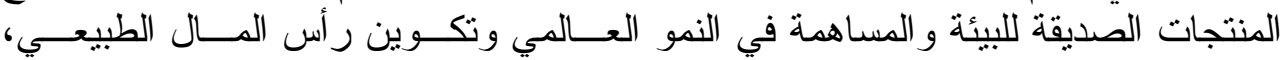
اسنتماره في المجالات البيئية الإجتماعية (Bismarck and Gurung, 2009, 7) لقد أدى سوئ الطئ 


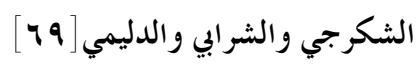

استخدام الدول و الثركات و الأفر اد المو ارد الطيبعية في سبيل تحقيق التتميــة الإقتصـــادية

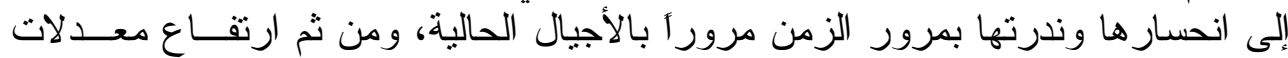

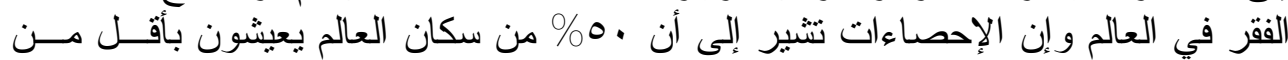

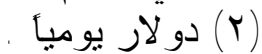

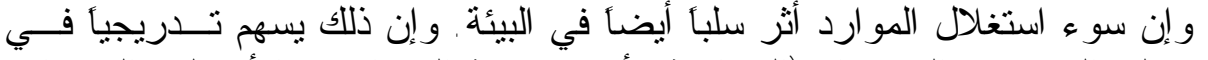

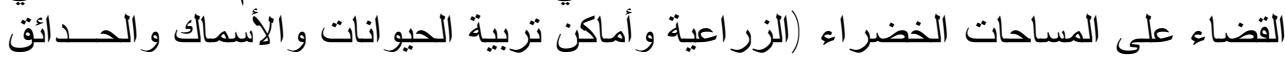

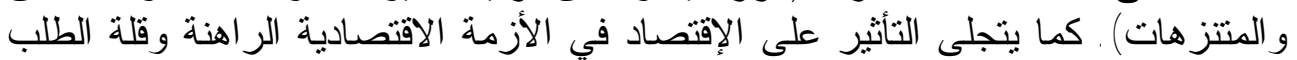

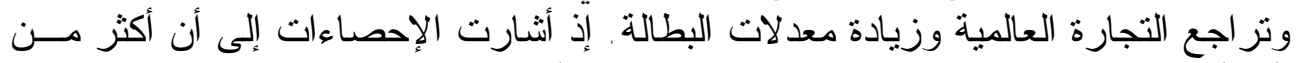

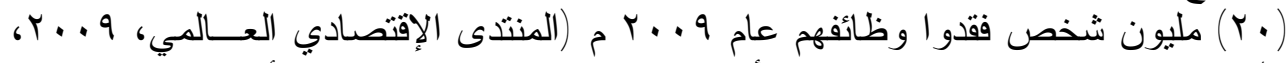

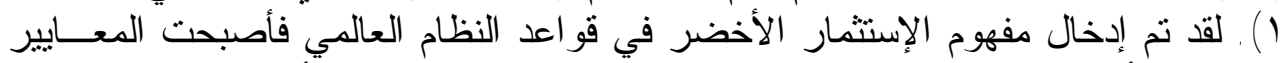

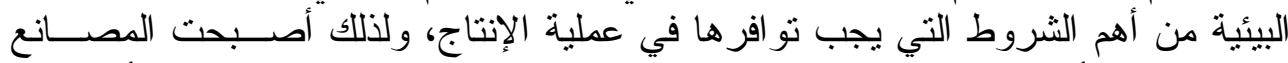

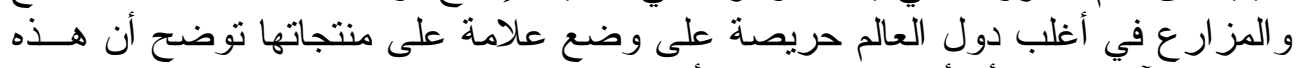

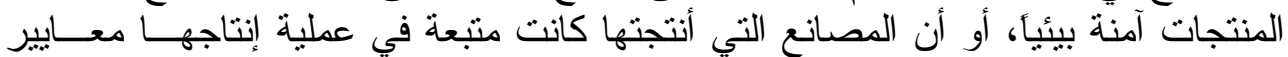

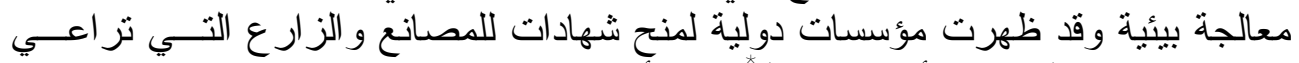

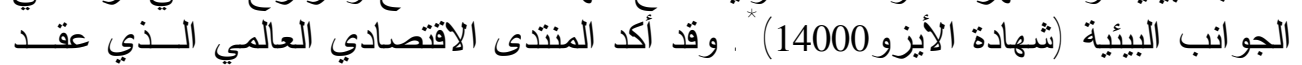

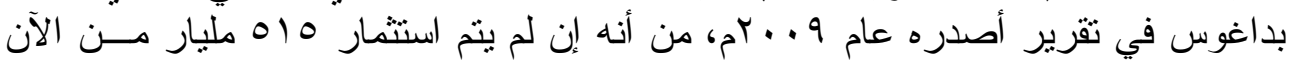

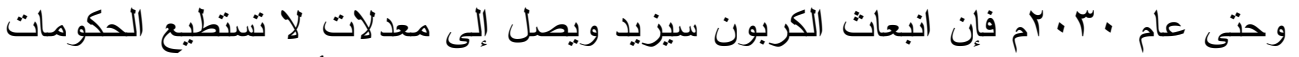

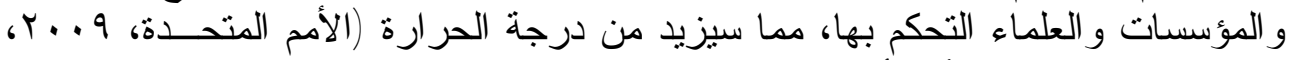
مائدة الاستثمار في منشأة الأعمال).

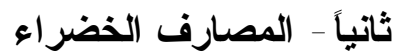

في السنو ات الأخيرة أصبحت بعض مؤسسات التمويل الدولية و المتعددة الجنسـيـيات

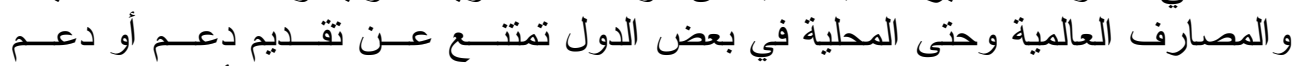

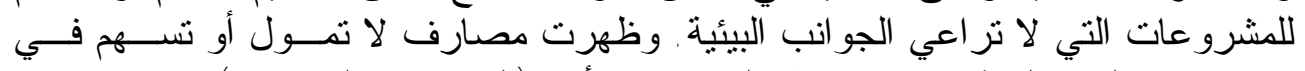

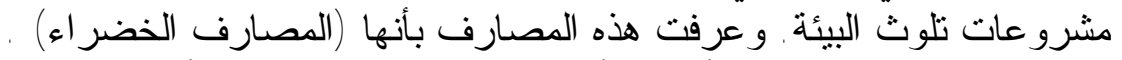

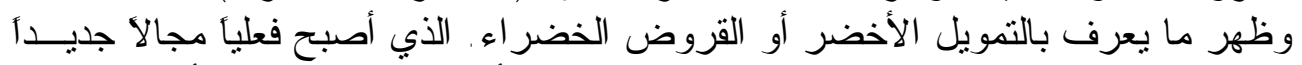

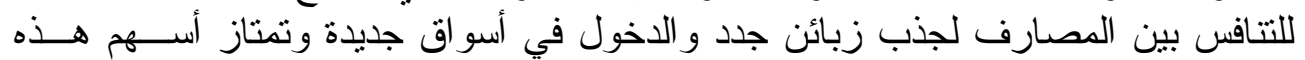

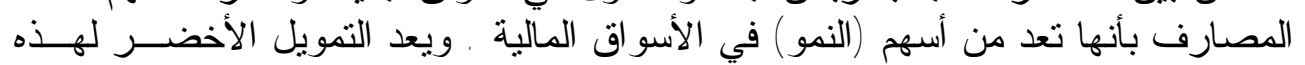

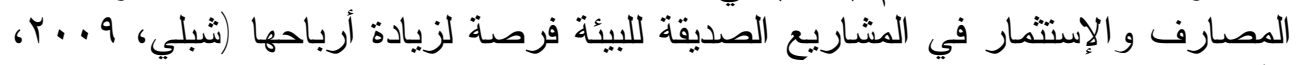

ثالثاً - الإستثمار الأخضر و البيئة المستدامة الإستثمار الأخضر أو الإستثمار مع أخذ المشاكل البيئية بعين الإعتبار هو ممارسة

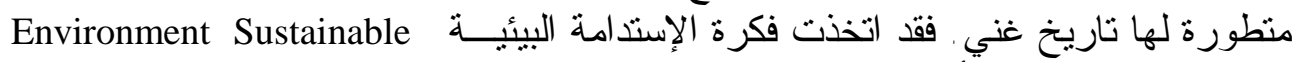

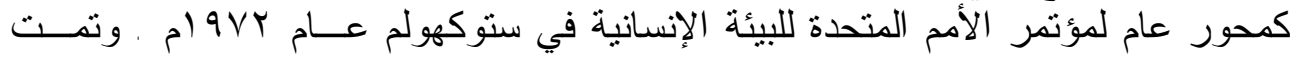




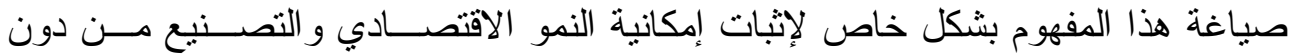

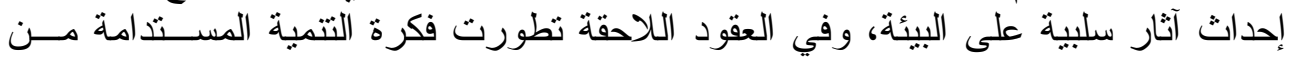

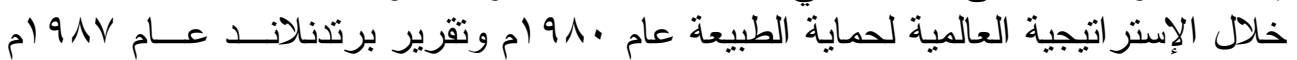

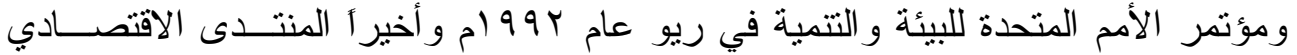

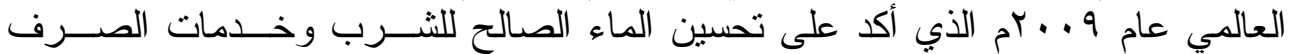

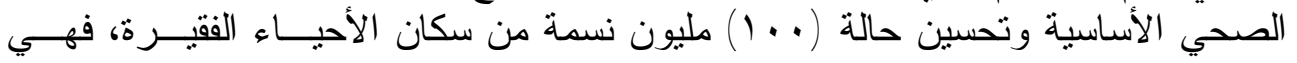

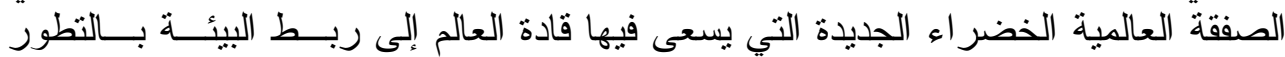

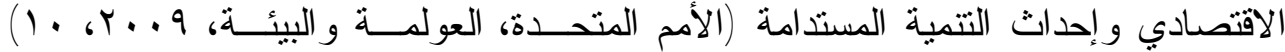

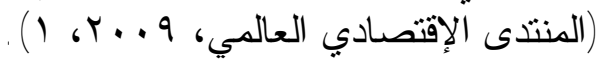

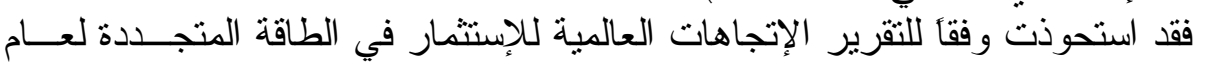

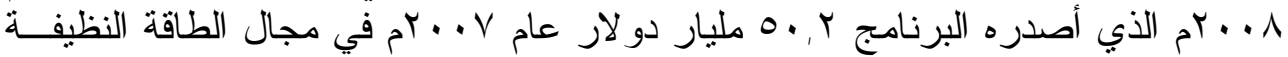

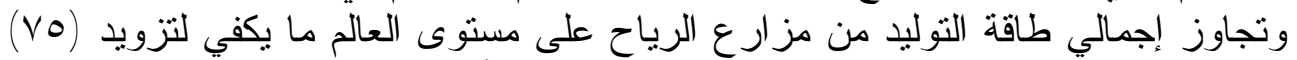

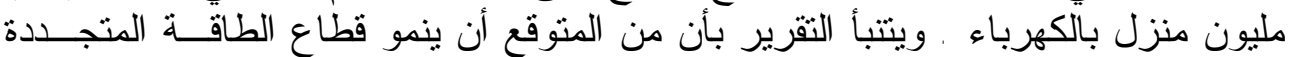

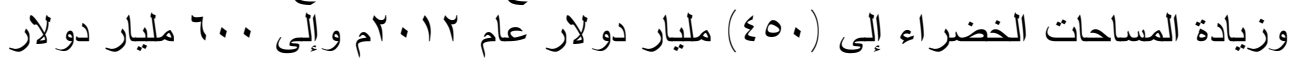

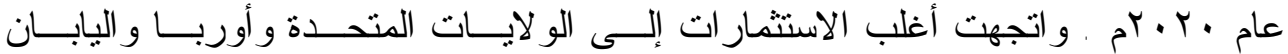

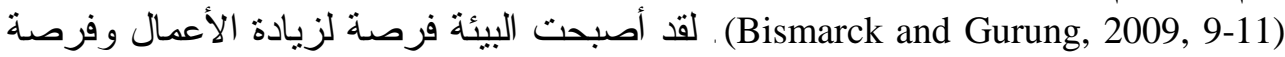

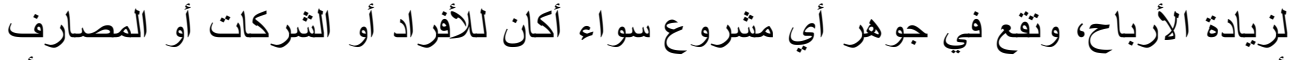

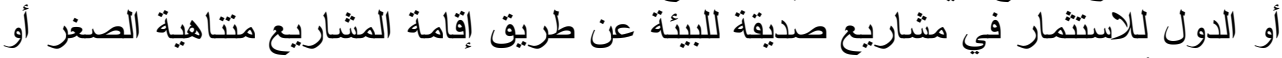

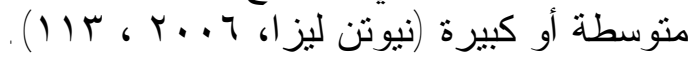

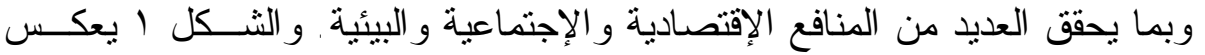




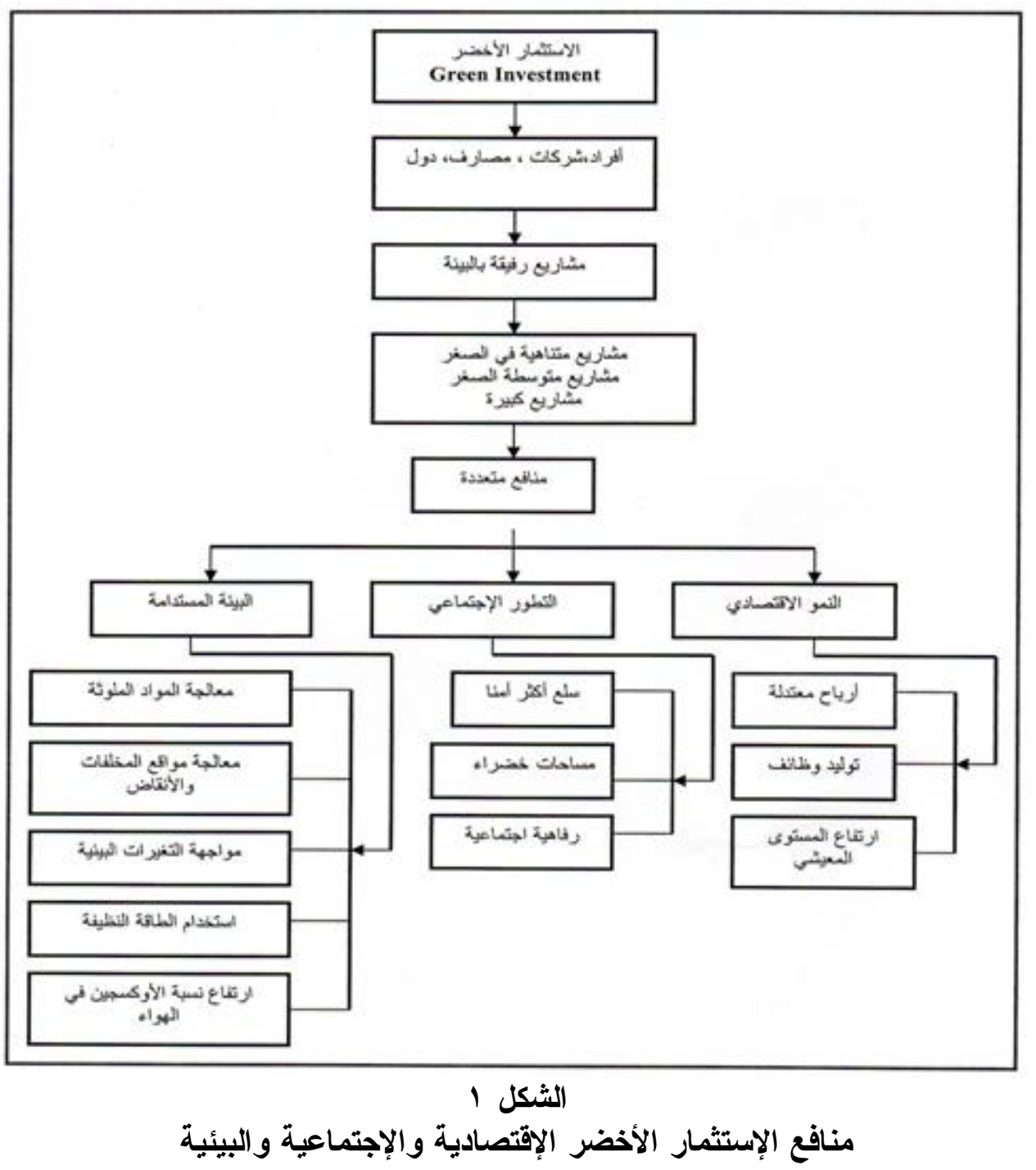

المصدر : من إعداد الباحثين بتصرف في شكل منلث النتمية المستدامة، واستتادا إلى المصدر : -Alawneh,ziyad 2007,Expert Group Meeting on Trade and Environment Priorities in the Arab Region, View of Civil Society Engaging civil Society on Prade and Environment Issues, Grand Hyatt Cairo.

- Katherine Pease and Associate ,2008,Green Investment Strategy Report, New York , Community Trust, July, P.9.

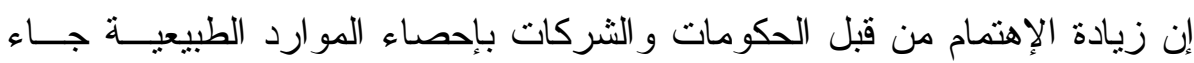

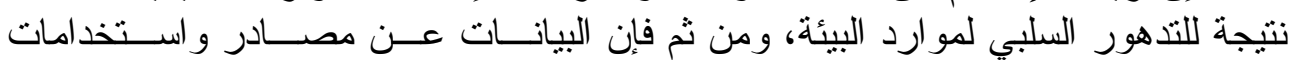

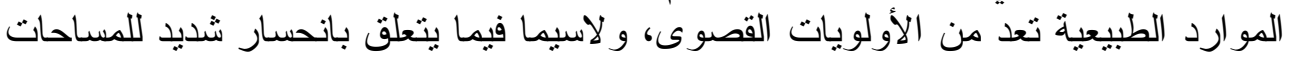


الخضر اء داخل حدود المدن وفي ضواحيها، مما أسهم في انخفاض نسب الغطاء الأخضر

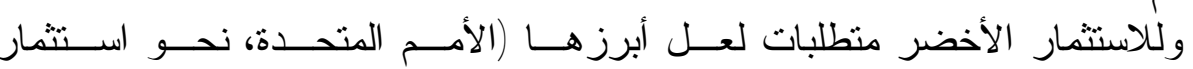

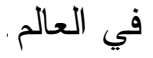

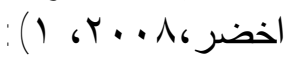

ا ـ إعادة تأهيل البيئة الإستثمارية التي تعمل بها المصارف و الثركات وتوظيف الأموال

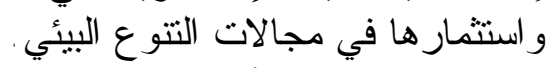

r. وضع السباسات و الأدوات المالية و إثنارات السوق القادرة على الانتقال إلى الاستثمار

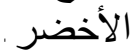
r. التقييم المستمر من قبل الحكومات و المصارف للخدمات البيئيــة و إدمــاج الحســابات الطبيعية في كافة الحسابات الاقتصادية و المالية. ع. ـ نوفير فرص عمل جديدة من خلال الوظائف الخضر الهاء.

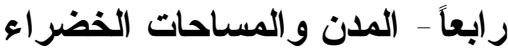

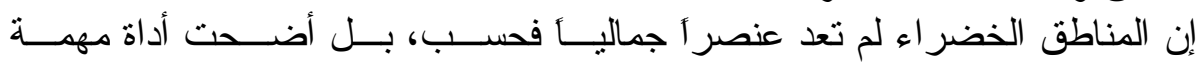

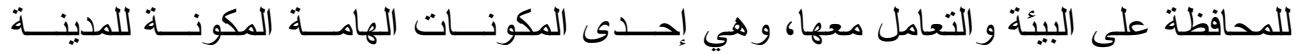

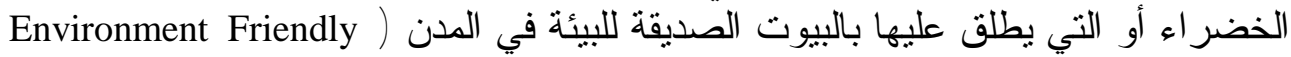
الأبو (Houses in Cities

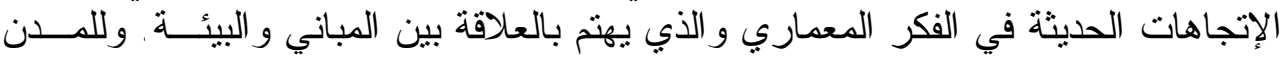

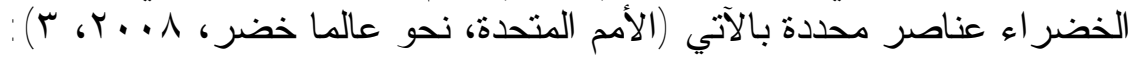

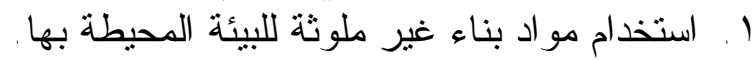

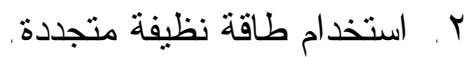
r. إنباع أسلوب علمي للتخلص من مخلفات البناء البناء و الفضلات.

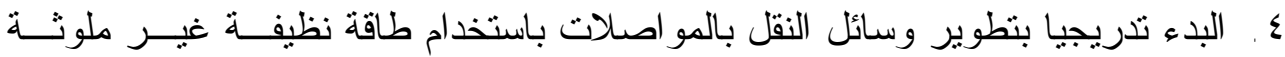

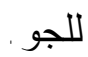
ه. خفض الانبعاثات الصادرة عن إز الة المساحات الخضر اء وتدهور ها.

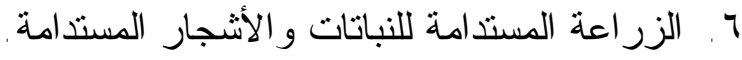

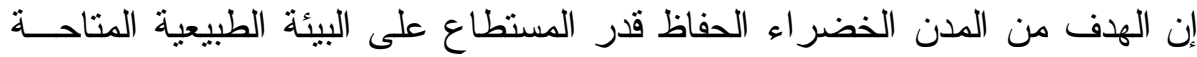

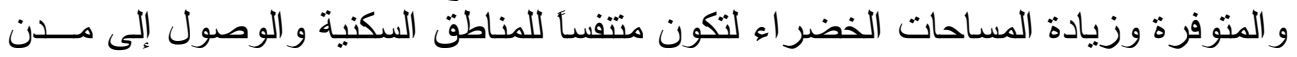

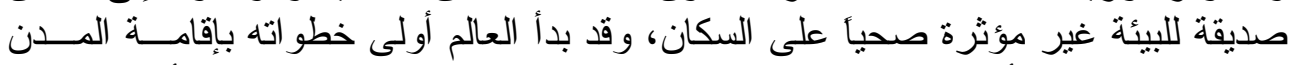

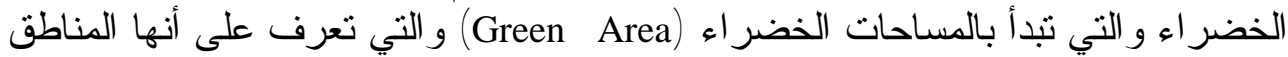

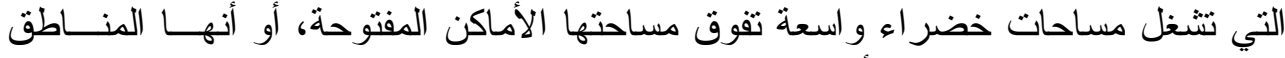

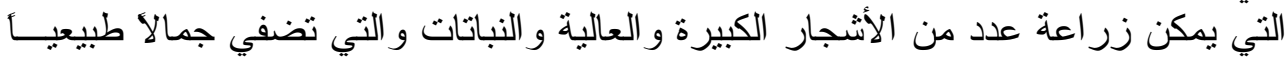

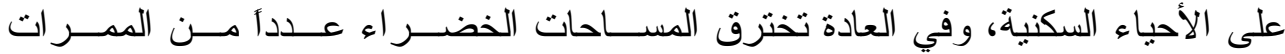

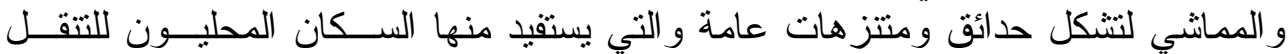

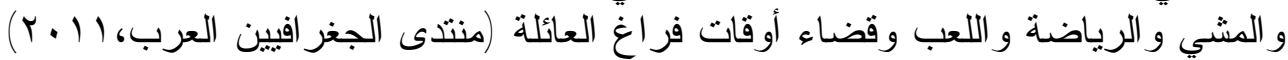

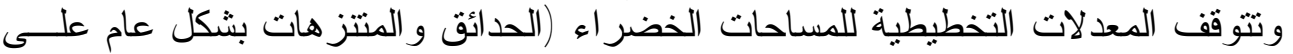

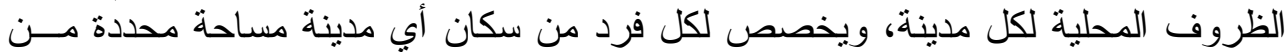

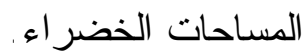


الشكرجي والشرابي والدليمي [Vr

وتتراوح المعدلات العالمية لنسبة المناطق المفتوحة من مساحة المجاورة الســانبانية

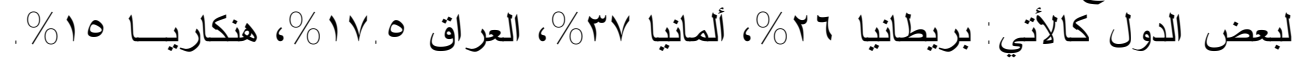

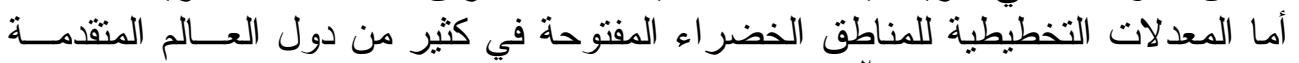

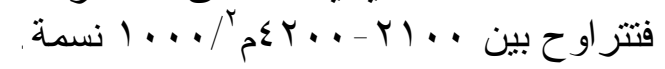

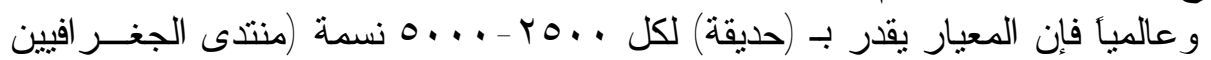

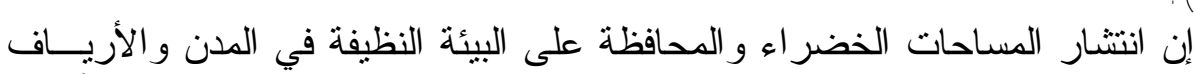

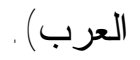

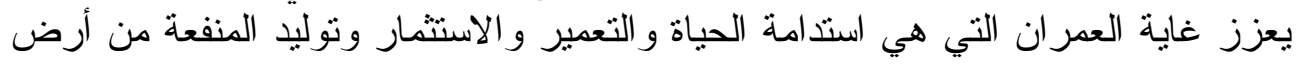

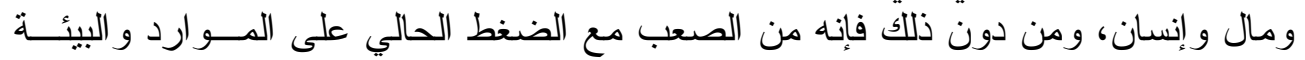

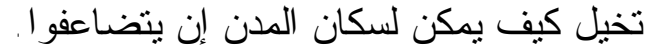

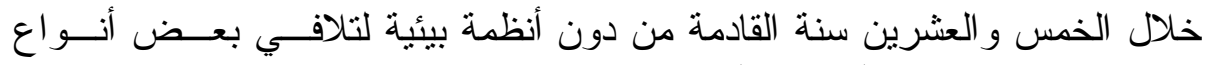
الإنهيار ات الإقتصادية و الايكولوجية و البيئية.

\section{أولاً - الإستثمار الأخضر في مدينة الموصل دراسة تحليلية للمساحات الخضر التضراء في المدينة}

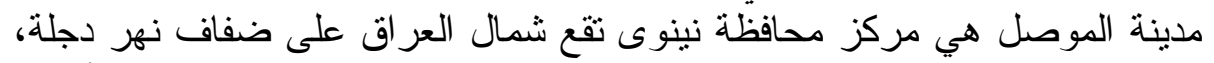

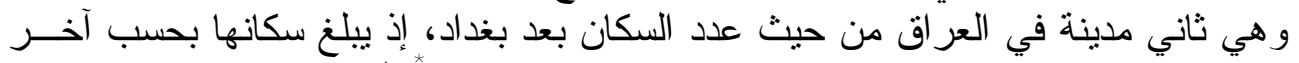

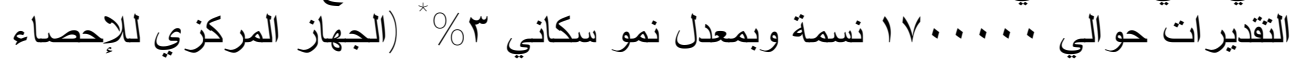

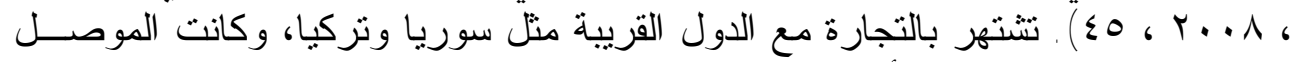

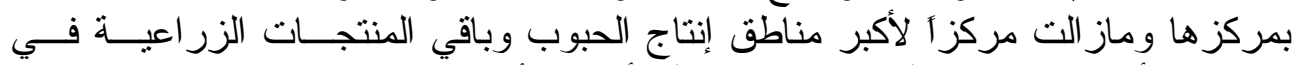

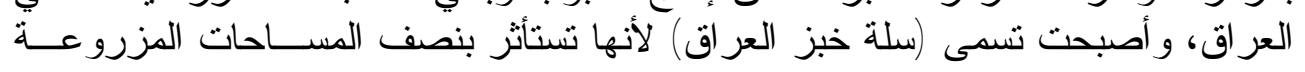

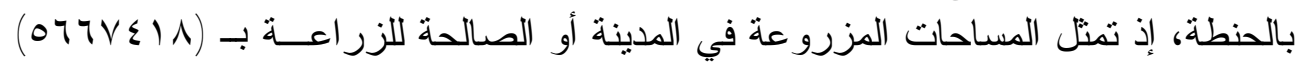

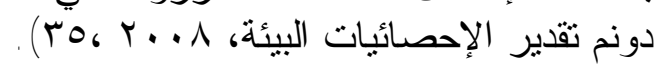

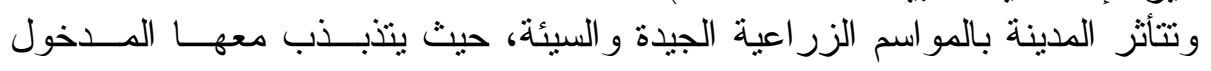

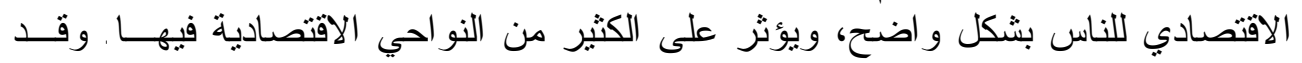

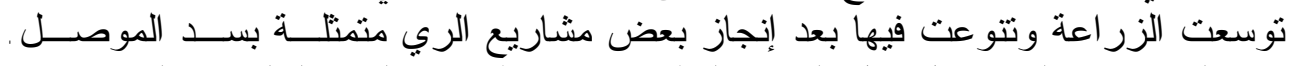

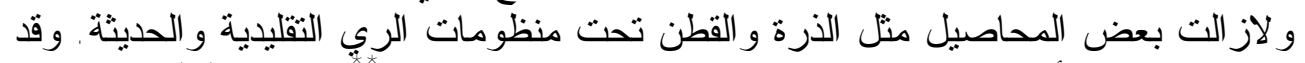

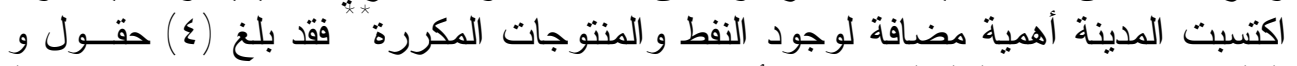

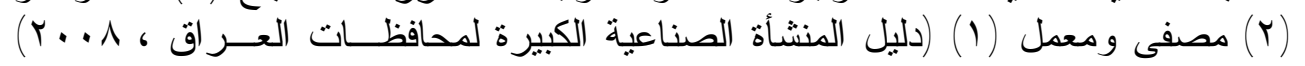

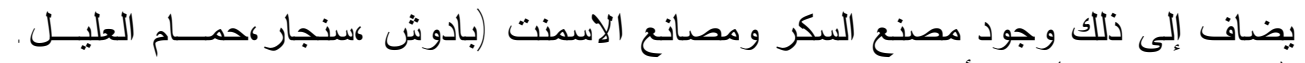

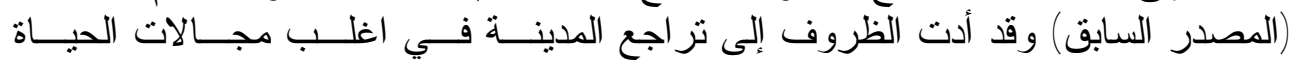

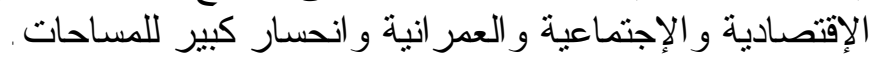

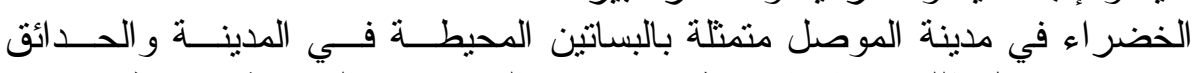

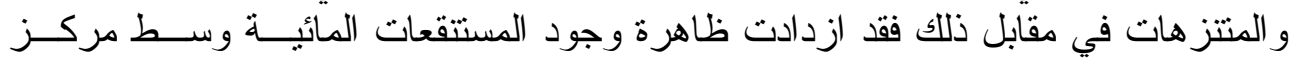

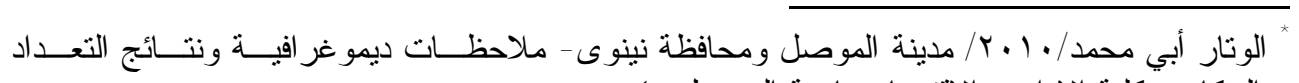

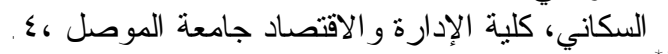
** المؤسسات النفطية لا تقع داخل مركز الدينة باستثاء معطل تعبئة الغاز بالقرب من سايلو الموصل .ع. 


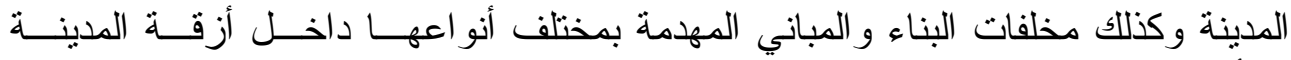

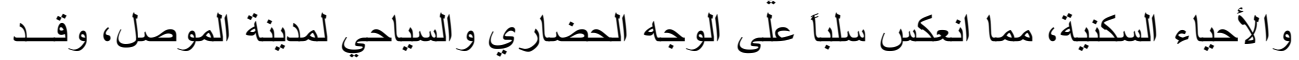

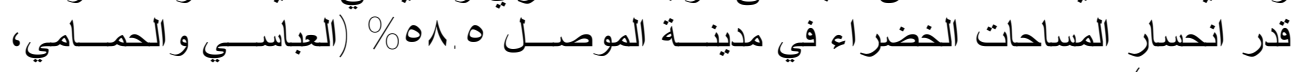
. ( $V$, r...V

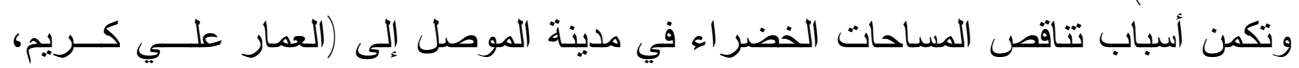

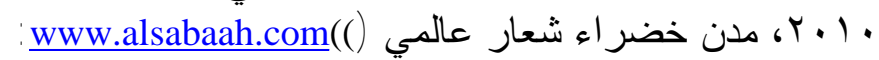

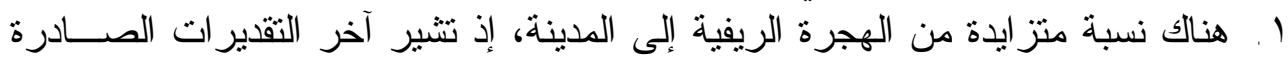

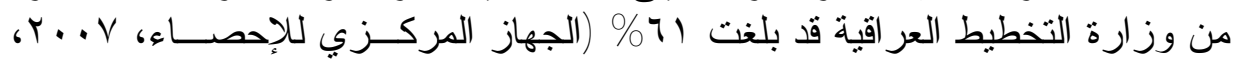

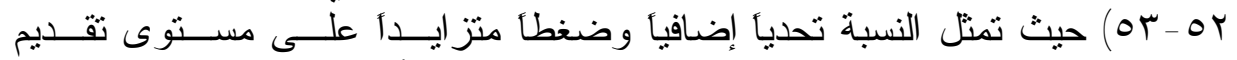

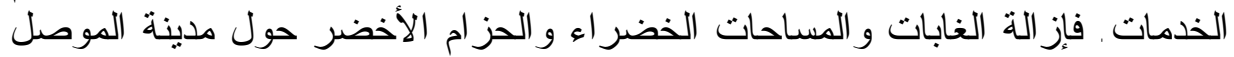

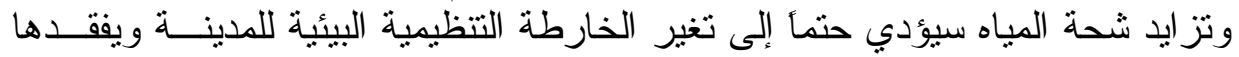
وجهرا الحضاري.

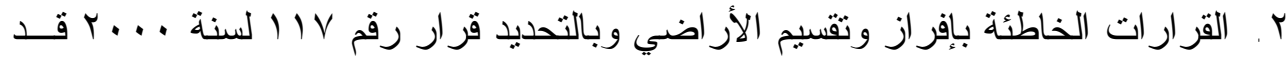

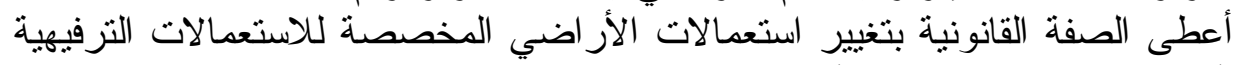

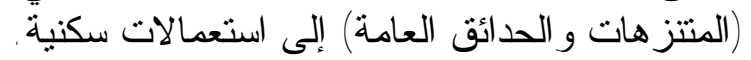

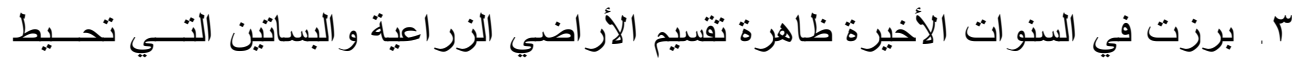

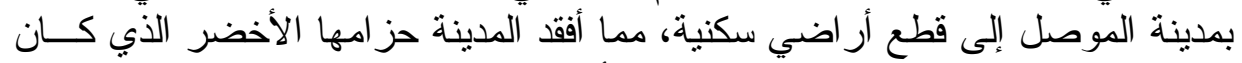

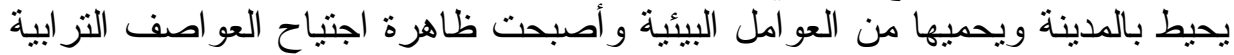

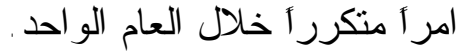

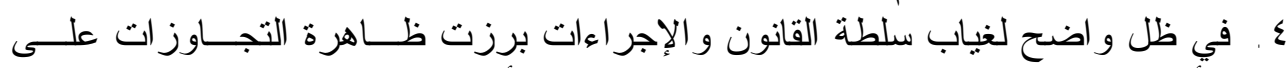

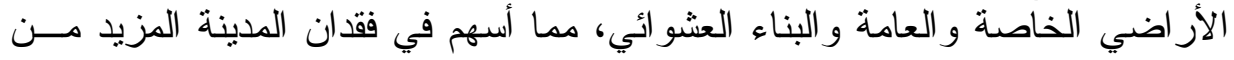

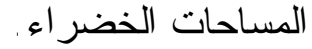

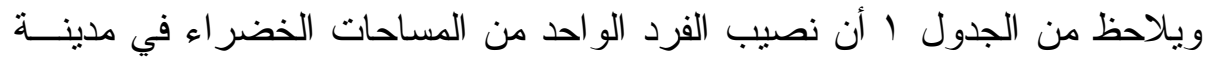

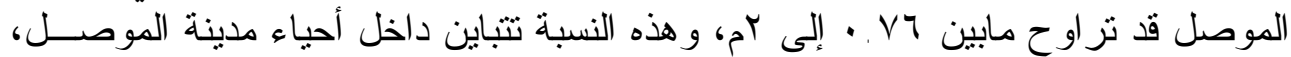

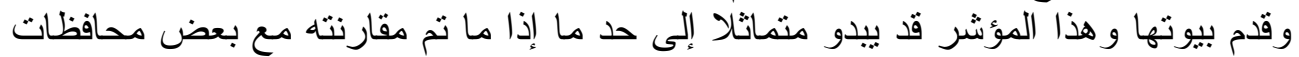

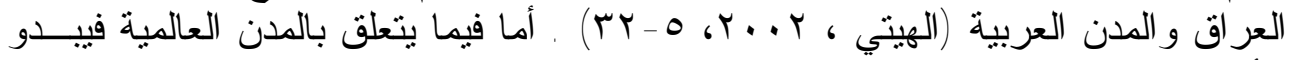

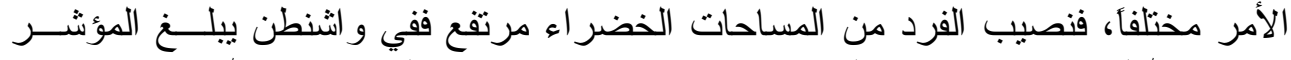

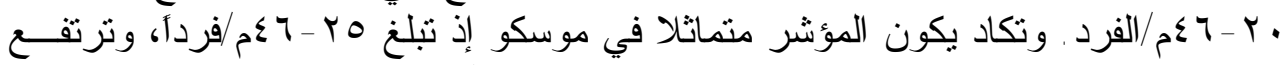

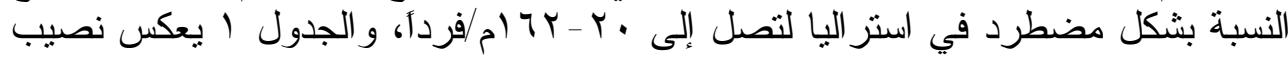

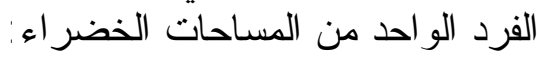

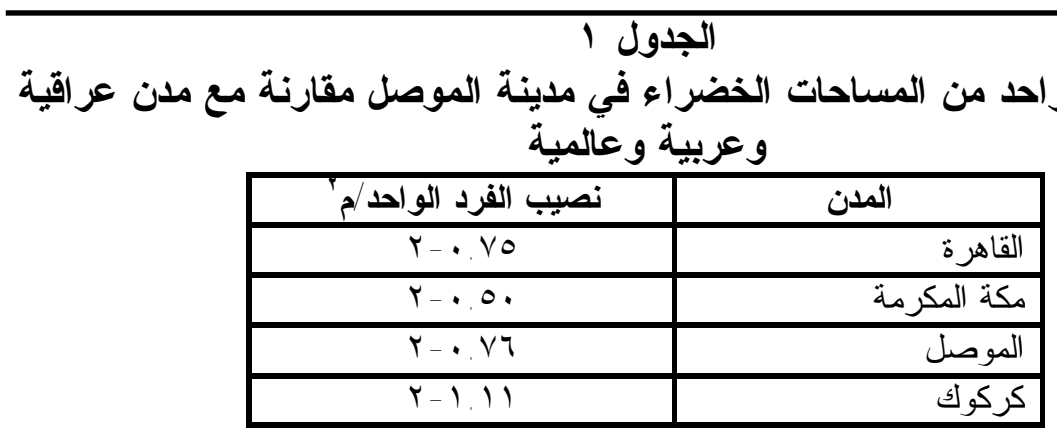


الشكرجي والشرابي والدليمي [V•

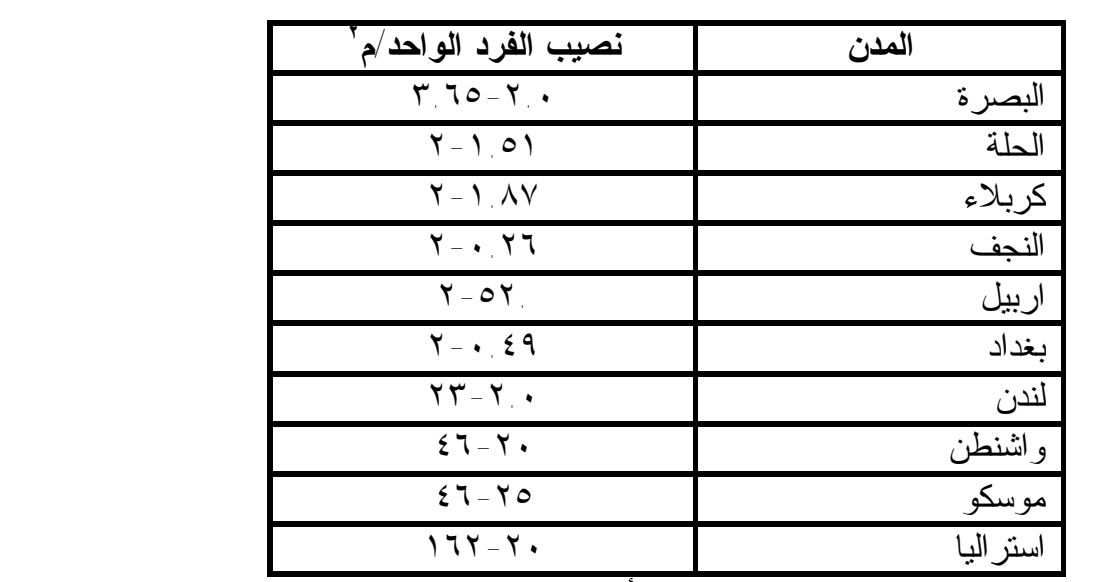

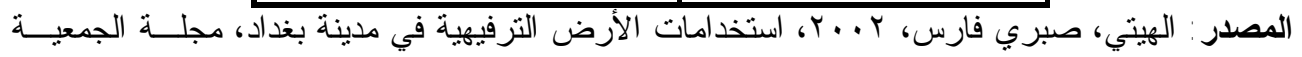

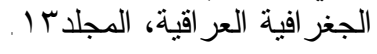

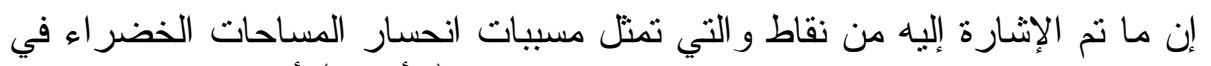

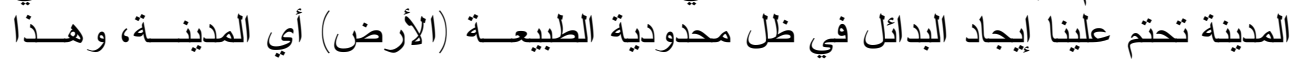

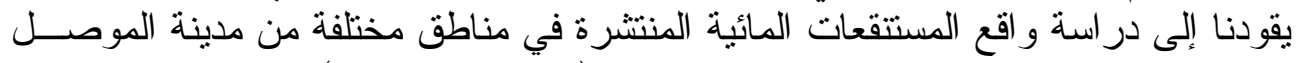

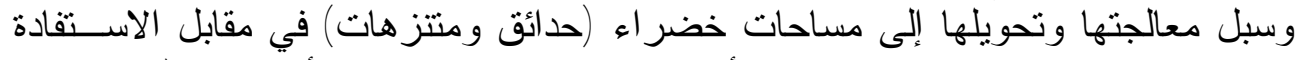

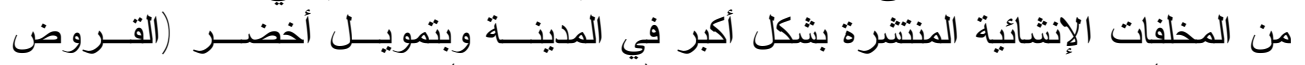
الخضر اء) من المصارف العاملة في الدينة (خاصة، عامة)

\section{ثانياً - واقع المخلفات الإنشائية و المستنقعات في مدينة الموصل

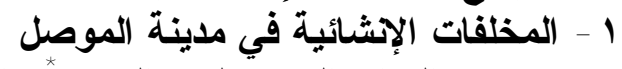

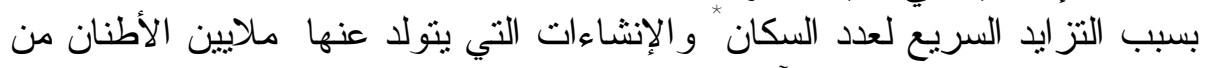

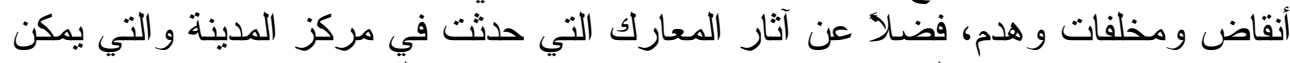

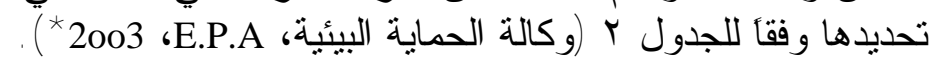

\begin{tabular}{|c|c|c|}
\hline \multicolumn{3}{|c|}{ 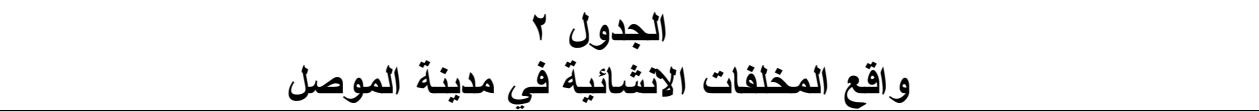 } \\
\hline طن لكل مشروع . . مقدم & وزن باوند /لمخلفات & ن المشروع \\
\hline 1.90 & 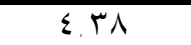 & بناء المنشأة السكنية \\
\hline $1 . .00$ & $\overline{\varepsilon \cdot \cdot T}$ & بناء المنشأة غير سكنية \\
\hline YVA. YO & $111 . r$ & هدم المنشأة السكنية (مسكن منفرد لكل عائلة \\
\hline rIV.O & TrV. & هدم المنشأة السكنية (الأبنية تحنوي على مساكن كثيرة) \\
\hline rAv. o & 100. & مخلفات الهام للمنشأة غبر السكنية \\
\hline
\end{tabular}

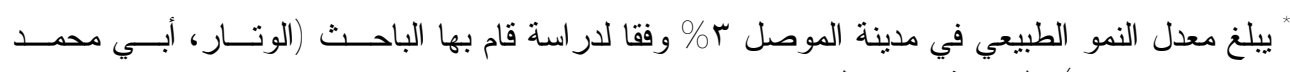

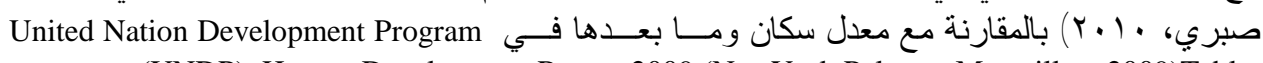
(UNDP), Human Development Report 2009 (NewYork:Palrrave Macmillan ,2009)Table. 


\begin{tabular}{|c|c|c|}
\hline$\varepsilon \varepsilon, Y_{O}$ & IV.Y. & مخلفات التزميم للمنشأة غير السكنية \\
\hline غير محددة & تختلف حسب نوع المشروع & ل رميم المنشأة السكنية \\
\hline
\end{tabular}

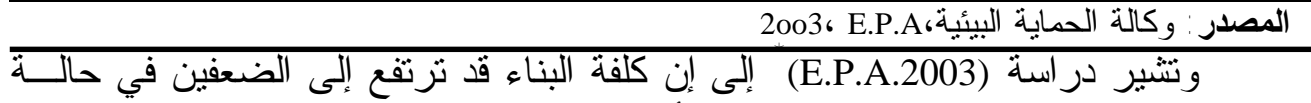

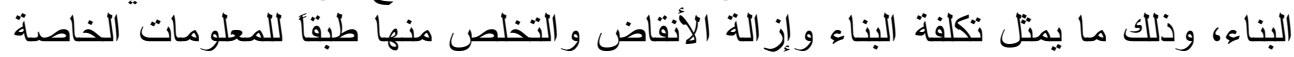

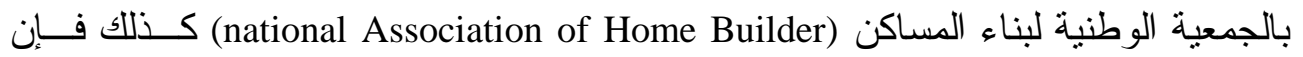

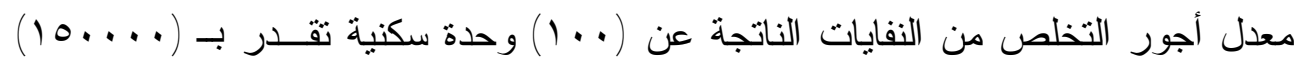

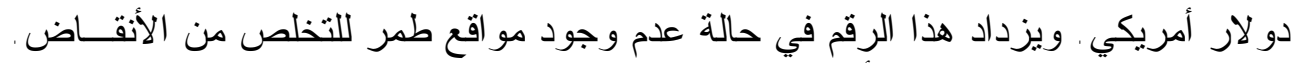

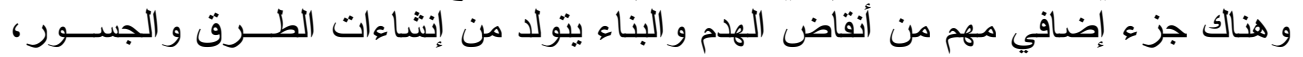

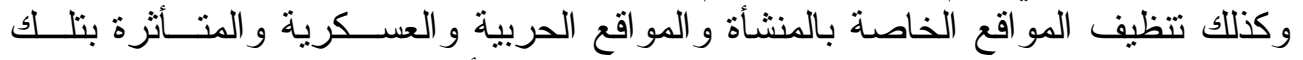

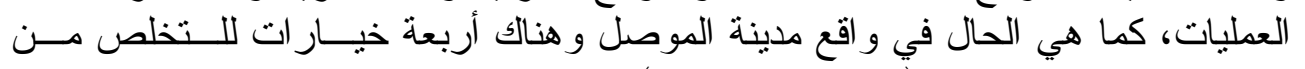

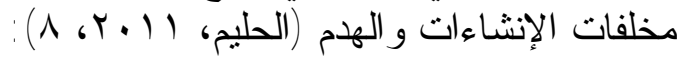

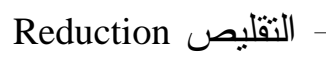
Recycle التدوير - إعادة الاستخدام Reuse -

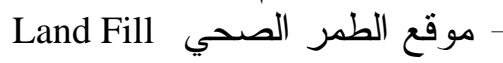

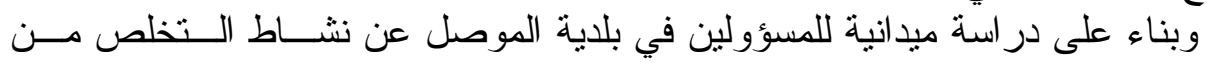

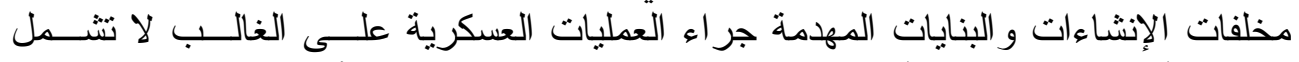

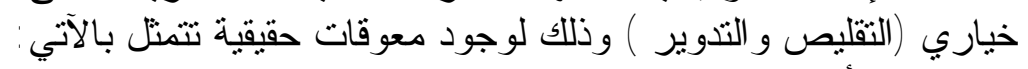
- تتطلب ري أس مال عال.

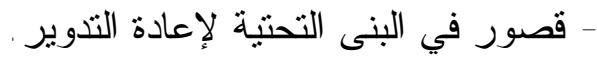

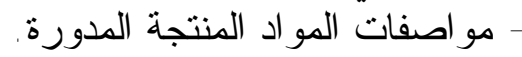
- تكاليفه مرتفعة قياساً إلى حجم الإنى المدرة المادات المنوقعة من عملية التدوير . - مجم المو اد المنتجة.

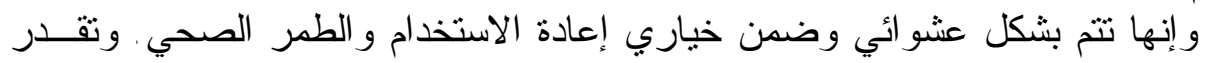

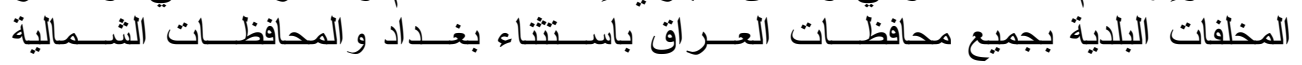

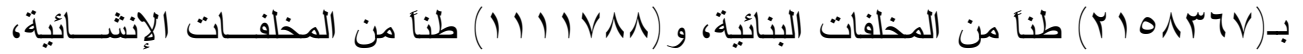

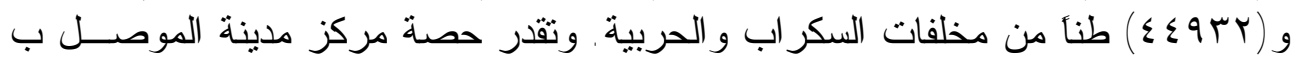

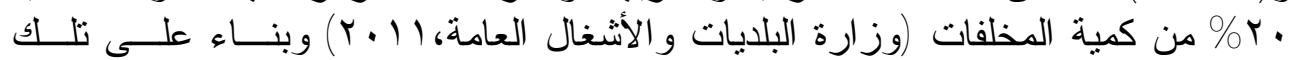

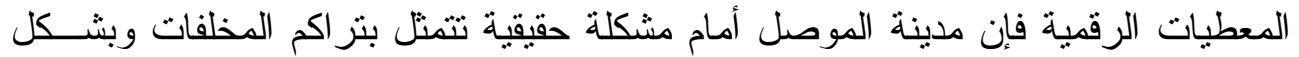

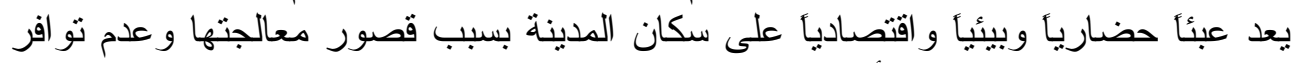

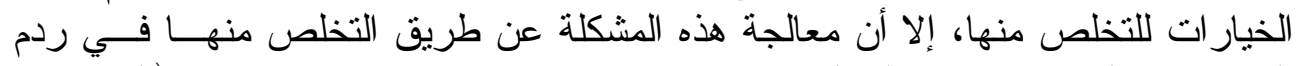

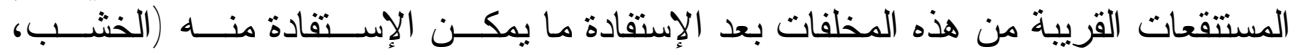

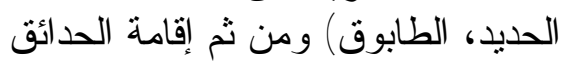

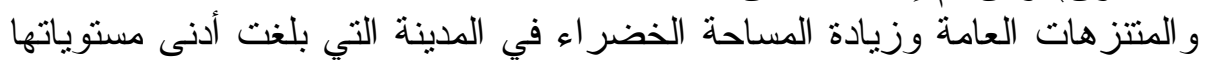

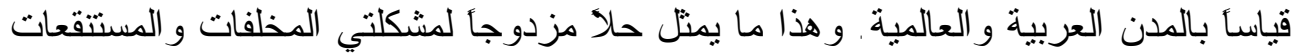




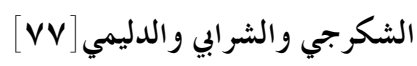

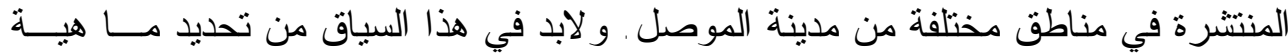

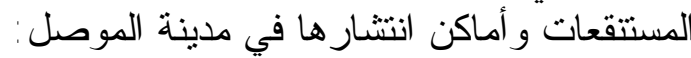

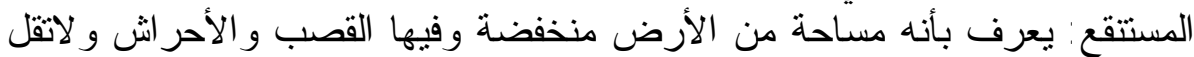

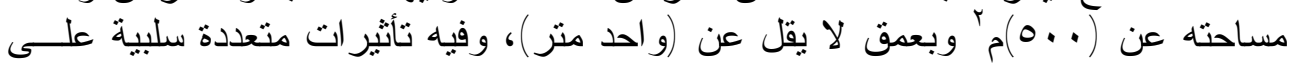

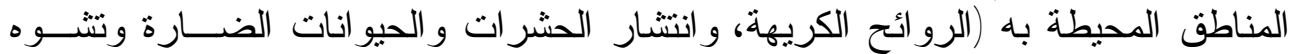

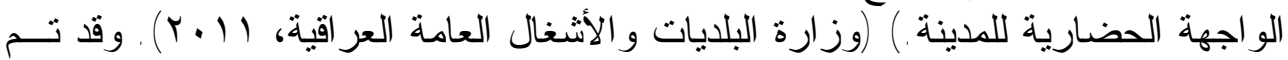

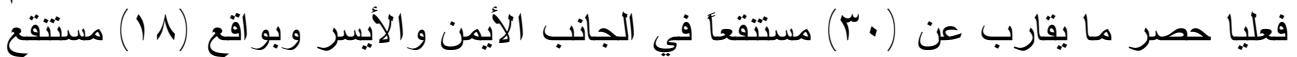

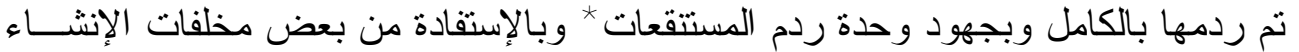

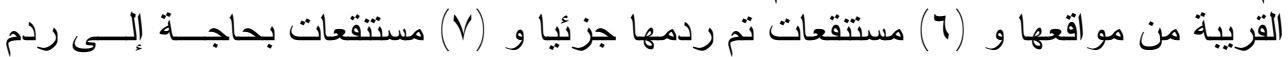

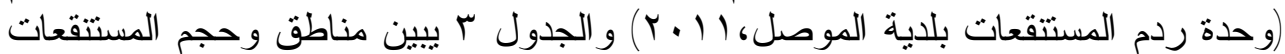

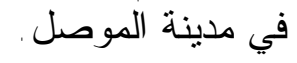

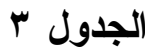

مناطق المستنقعات وكمية المخلفات التي تحتاجها من الردم في مدينة الموصل

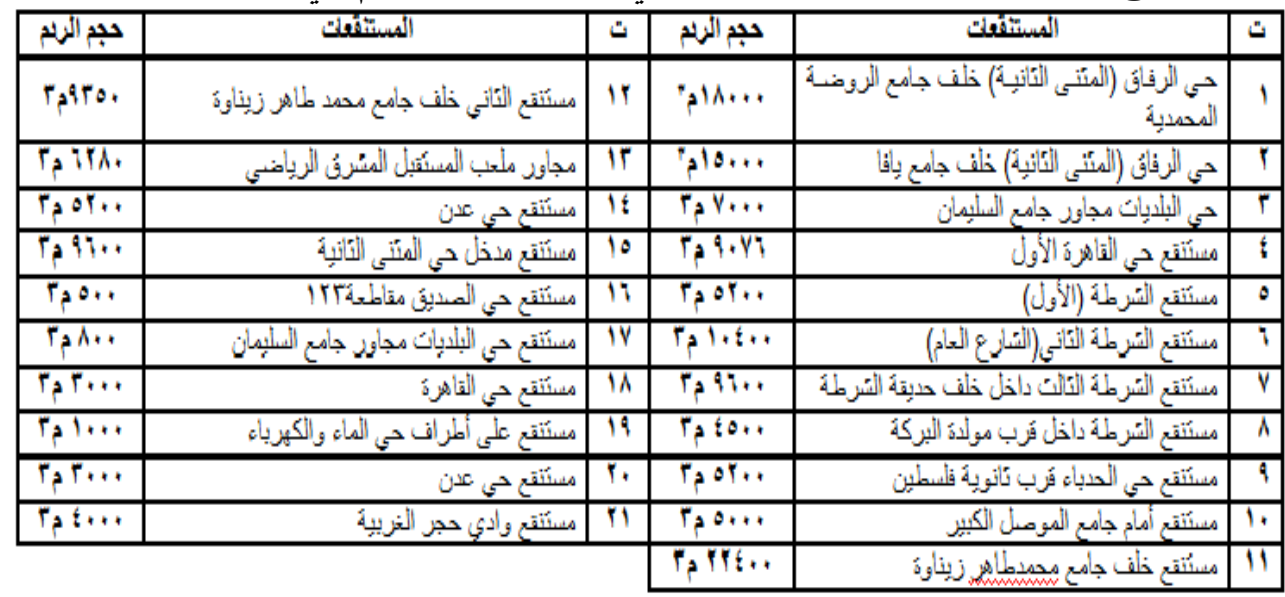

المصدر : وحدة ردم المستتقعات بلدية الموصل، I | ـ ؟ .

و لابد من الإثارة في هذا الصدد إلى أنه قد تم فعليأ تشكيل (وحدة ردم المستتقعات)

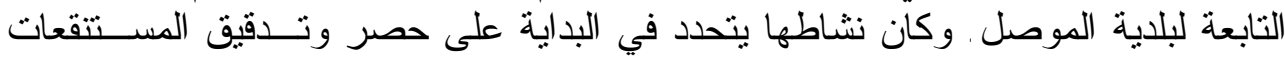

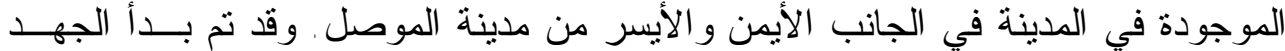

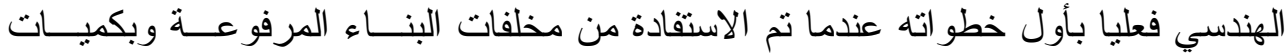

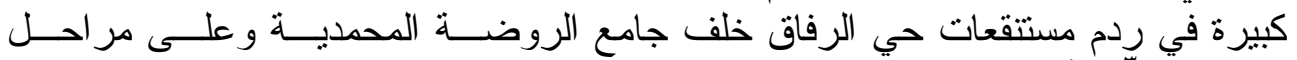

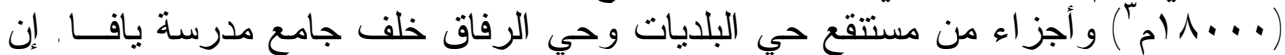

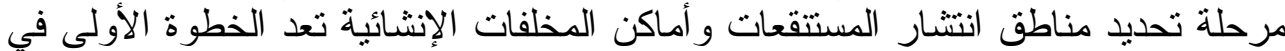

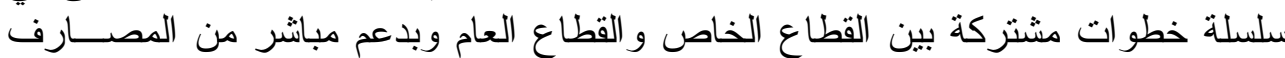

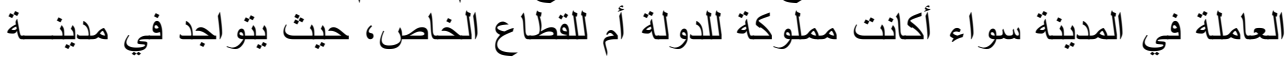

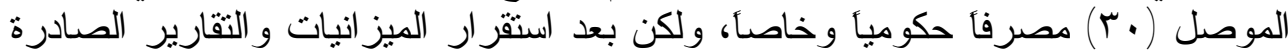

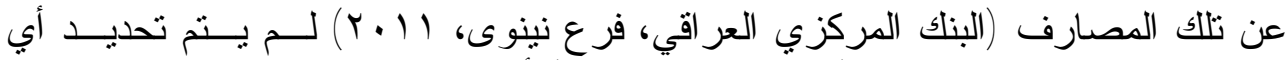

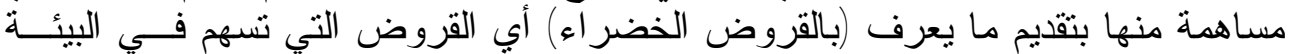




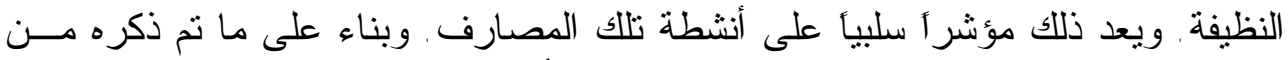

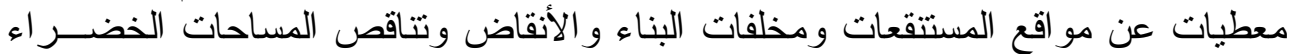

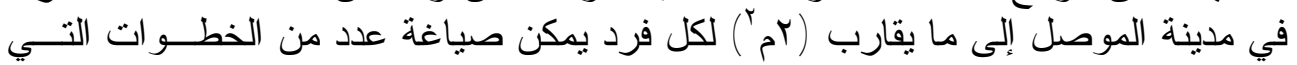

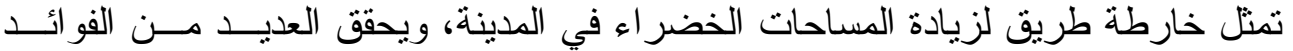

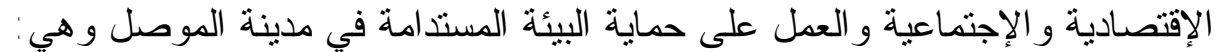

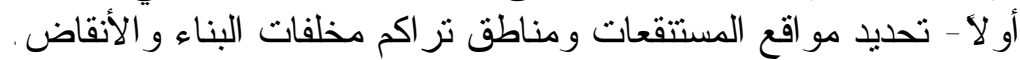

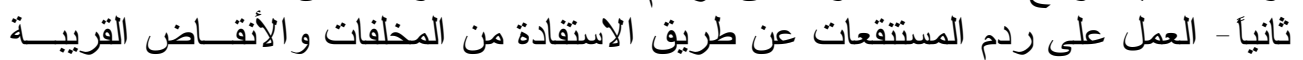

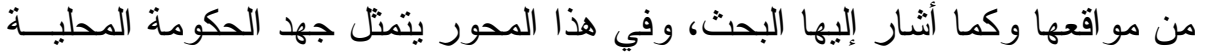

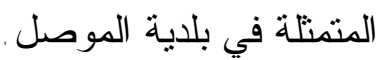

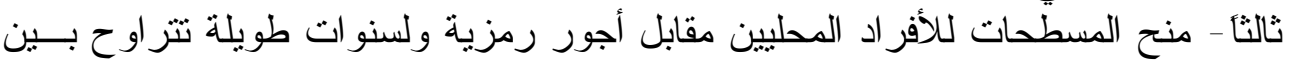

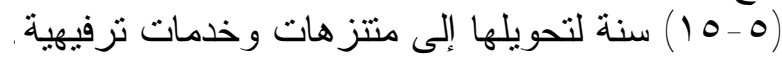

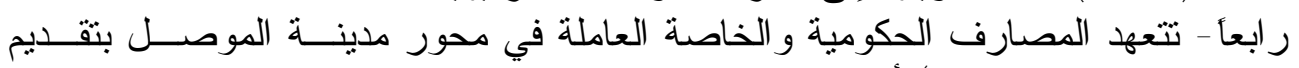
القروض الخضر اء) أبي القروض التهاء التي تسهم في بيئة نظيفة.

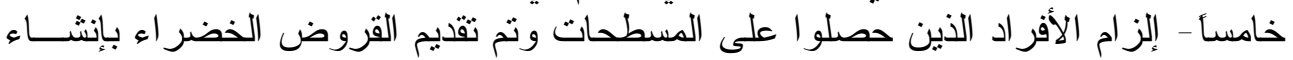

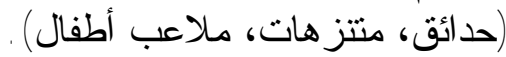

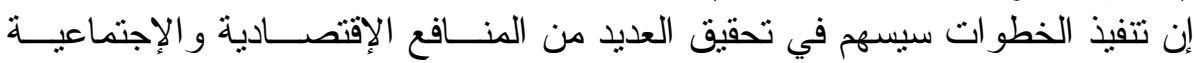

وحماية البيئة المستدامة، و الثكل ب بعكس المنهجية التي يسعى البحث إلى تحقيقها خدمسـة الإنة

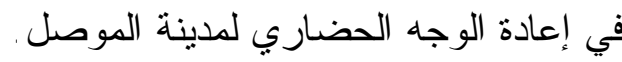

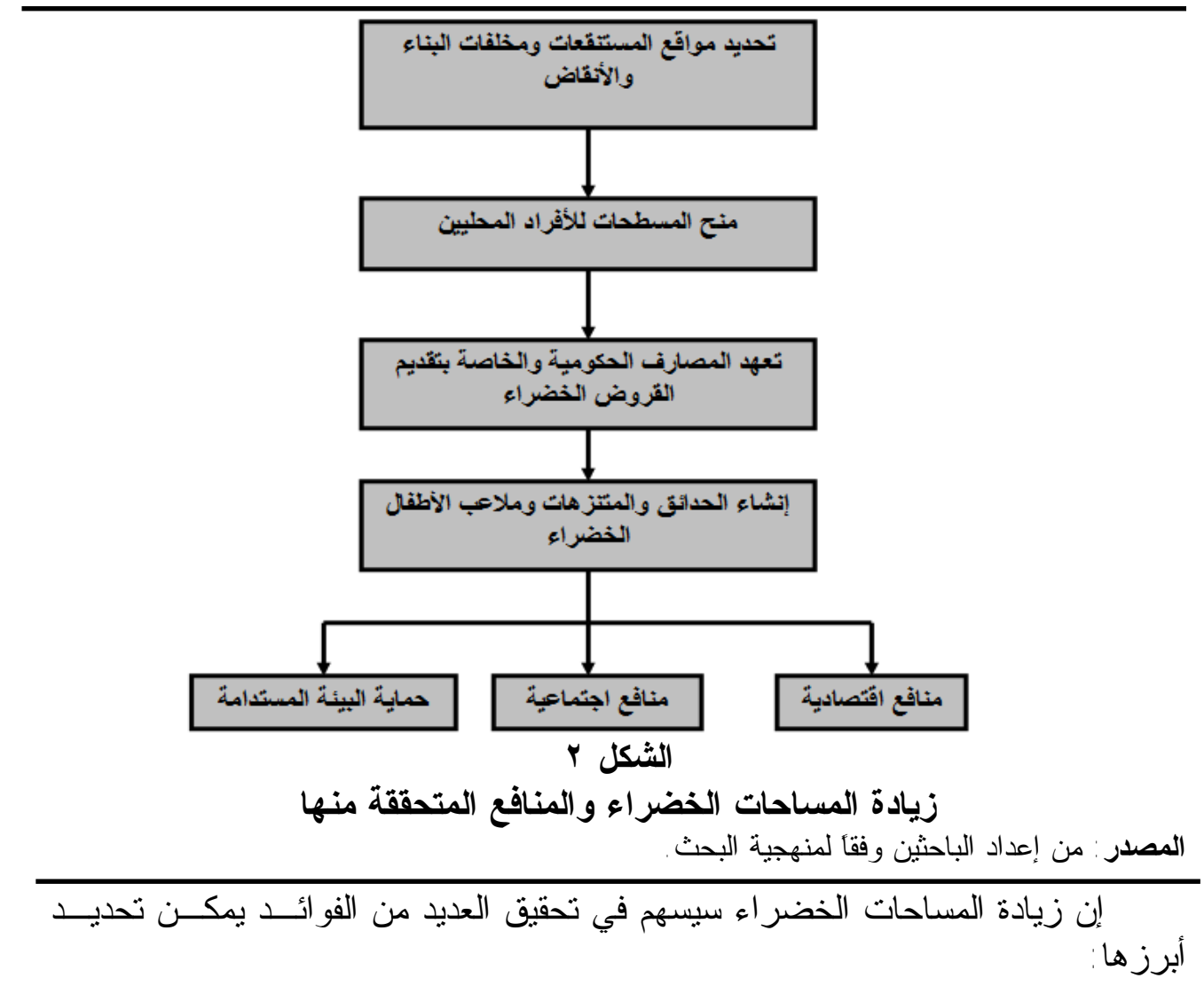




\section{ا 1 - المنافع الاقتصادية}

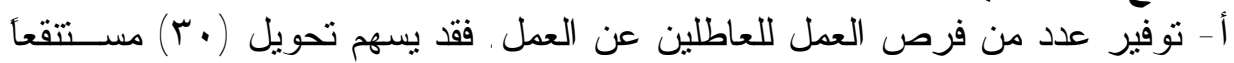

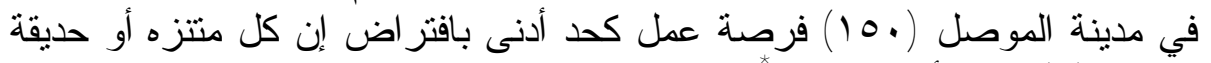

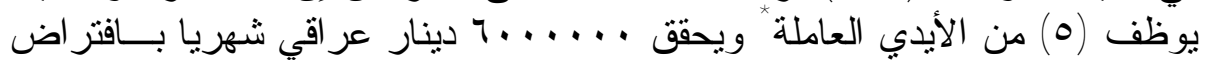

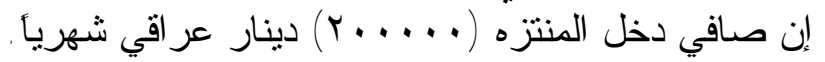

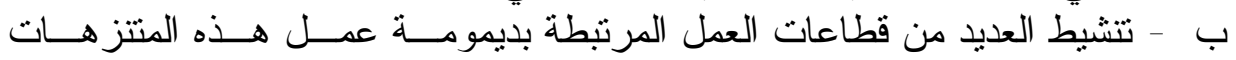

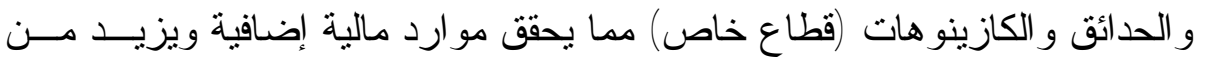
فرص العمل في المدينة.

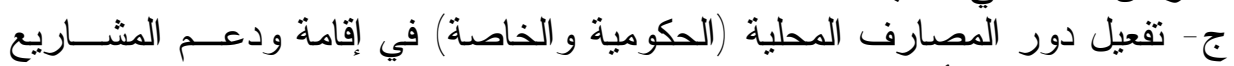

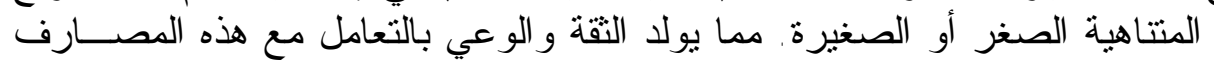

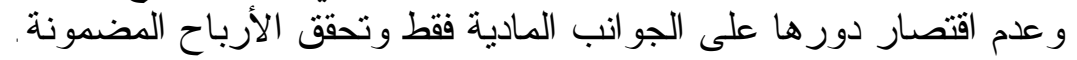

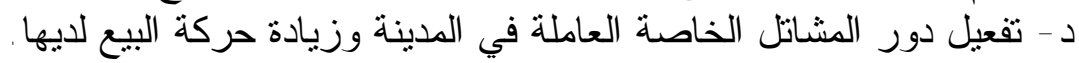

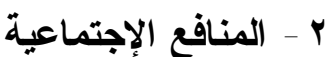

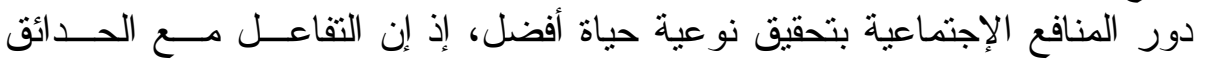

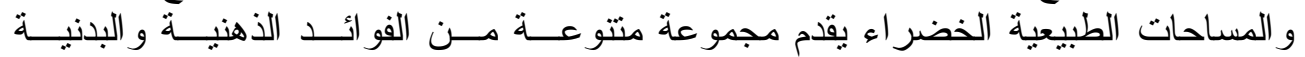
و الإجتماعية للمو اطنين . فالحدائق العامة تعد الأماكن الأمتل للأطفـــال و الثـــباب وكبــــار

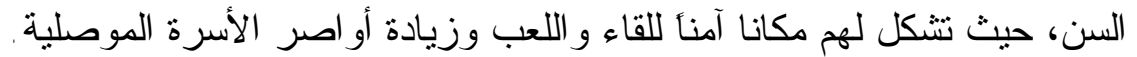

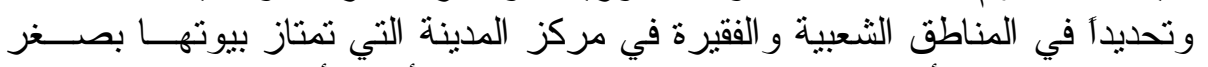
مساحتها وقدمها وضيق أزقتها و انخفاض مستوى الدخل لدى ألى أغلب أسر ها.

\section{r - الحماية المستدامة للبيئة}

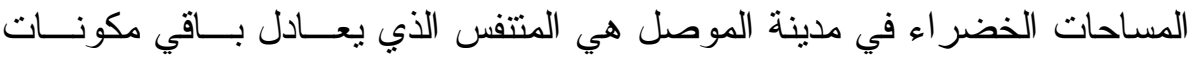

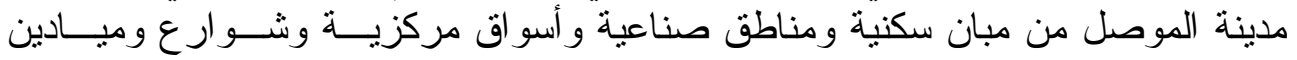

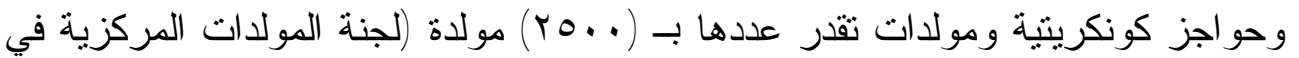

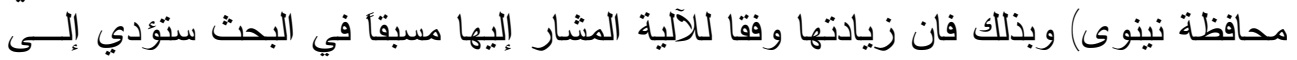

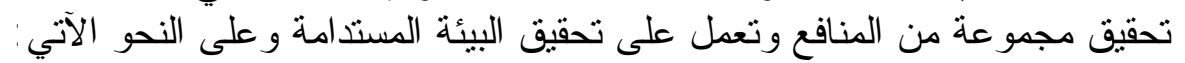

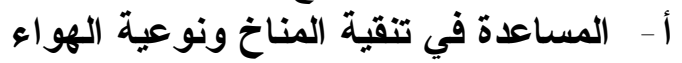

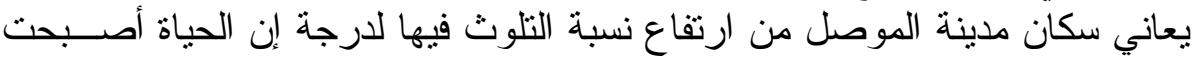

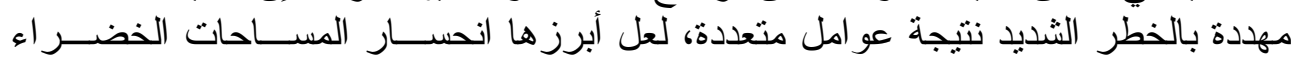

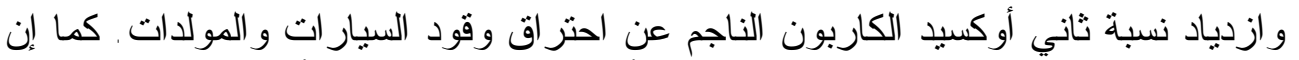

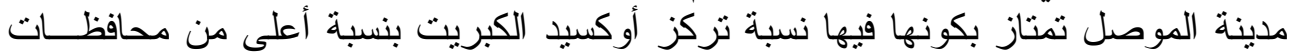

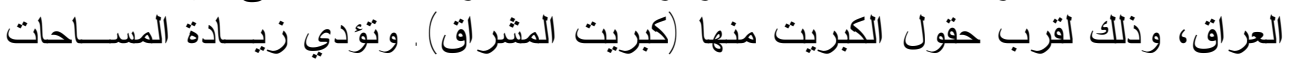

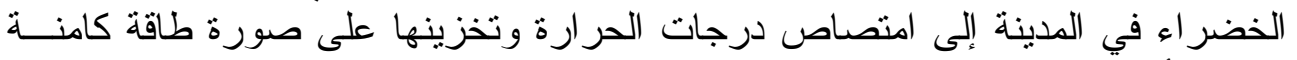
تستخدم أثناء تبخره، وهذا يجعل ميزان الطاقة موجبأ وحر ارة الجو معتدلة. 
ب -زيادة المساحات الخضر اء يسهم بزيادة نسبة الأوكسجين في المدينة

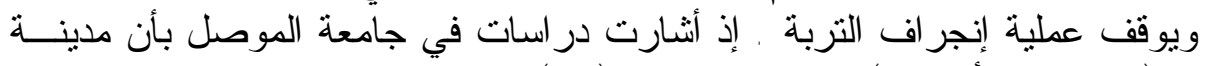

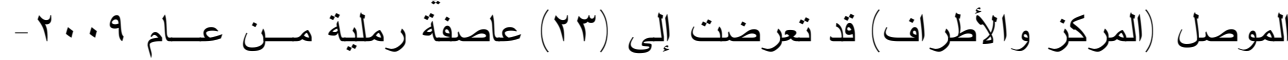

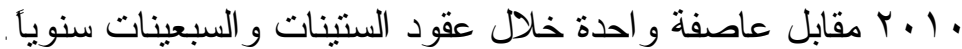

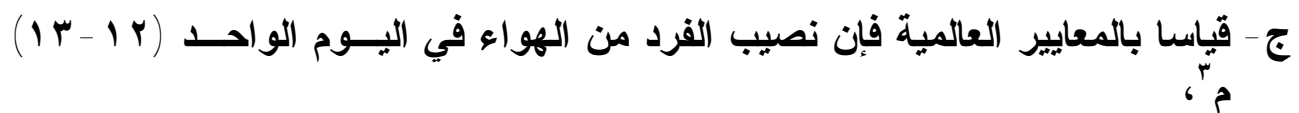

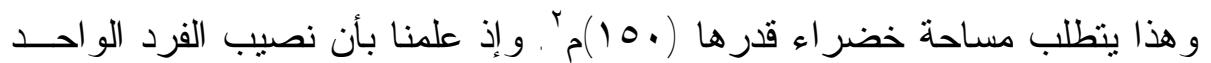

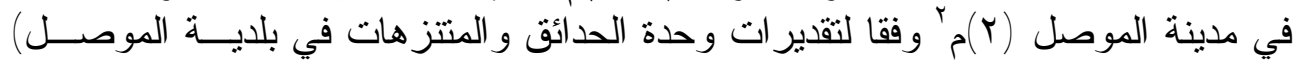

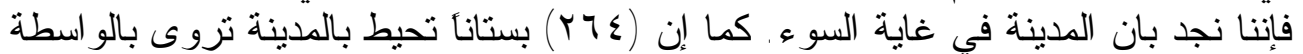

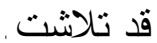

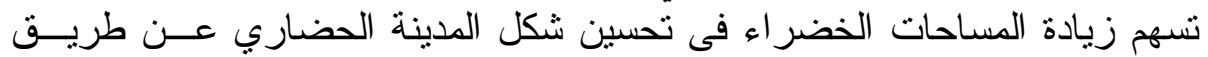

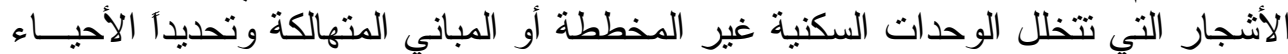
الشعبية و الفقيرة.

هـ - الحفاظ على التتوع البيولوجي من خلا تأمين مساحات للطيور المهاجرة

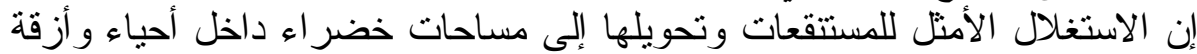

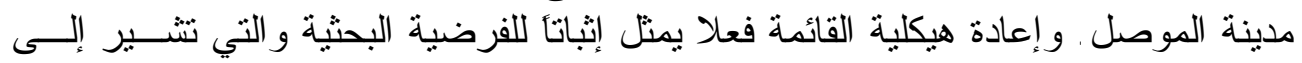

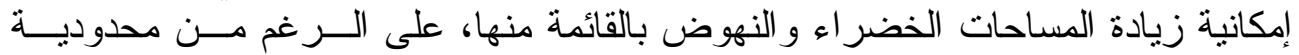
الأرض داخل حدود المدينة.

الإستتتاجات

ا . برتبط مفهوم الإسنتمار الأخضر بممارسة الأخلاق البيائية التي تقود حتمـــا للإزرتقــاء

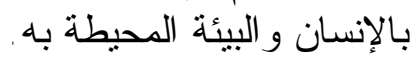

r ب يتجلى مفهوم الإستتمار الأخضر في الفو ائد الإقتصادية والإجتماعية الضخمة الناتجـــة

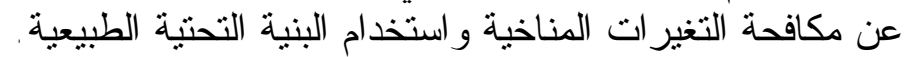

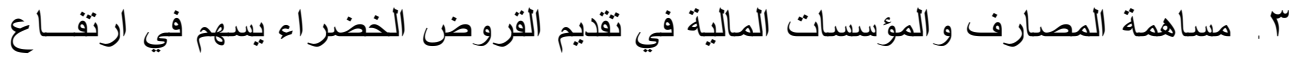

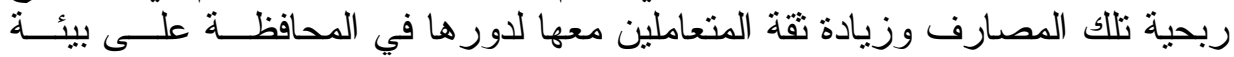
نظيفة.

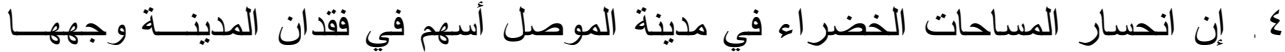
الحضاري . وزيادة نسب التلوث في المدينة و أنثر نفسياً واجتماعياً على أهالي المدينة. 0. تحديد مناطق المستقعات و أحجام المخلفات و الأنقاض في مدينة الموصل يمثل حــلا مزدوجا للمشكلتين معأ.

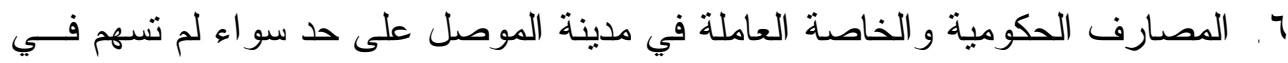

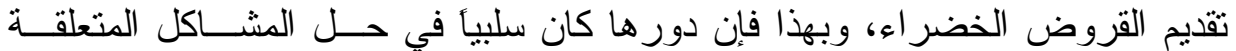

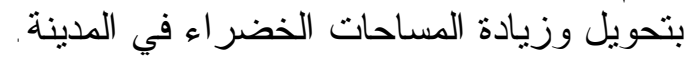

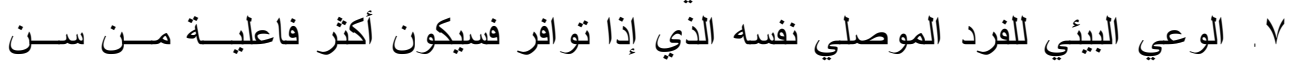

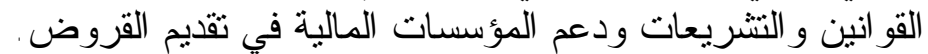


الشكرجي والشرابي والدليمي ا ام]

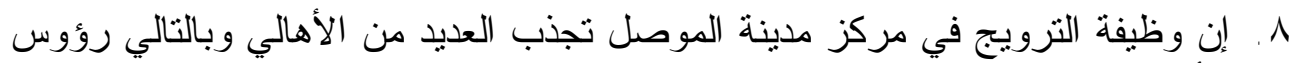

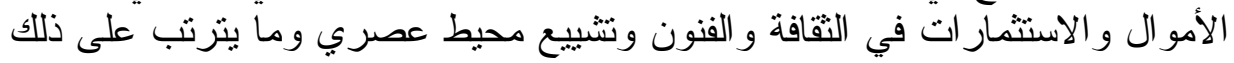

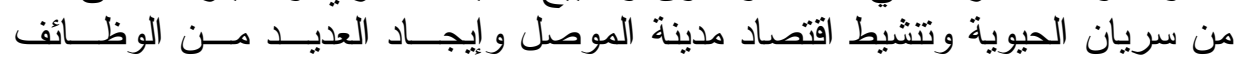
الجديدة.

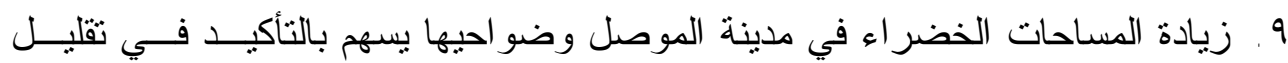

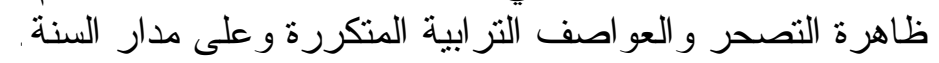

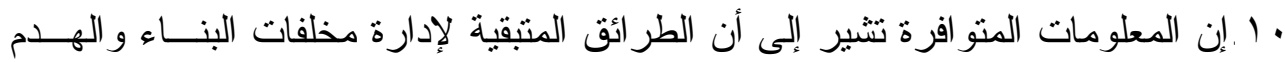

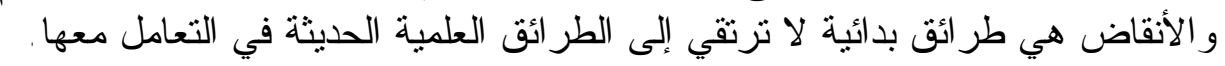

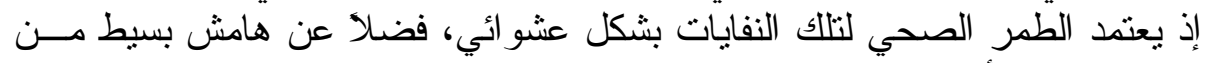
عملية إعادة استخدام أو تدوير تلك المخلفات.

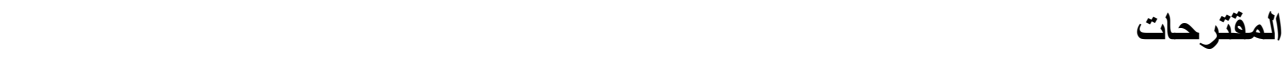

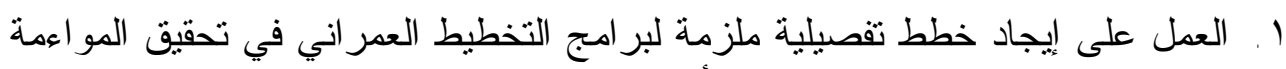

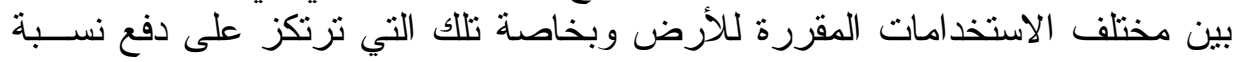

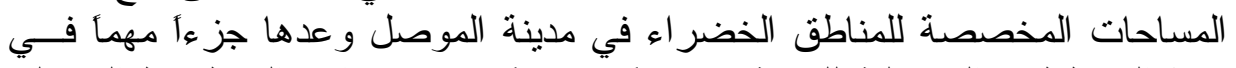

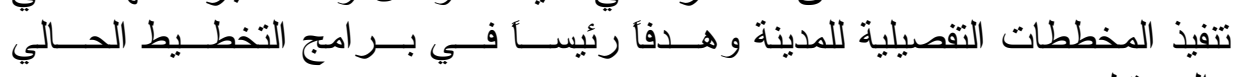

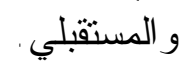

r. زيادة الوعي الاستثماري في مجال الحدائق و المتنزهات وتقدير العائد الاقتصادي لها. وتوفير البيئة الأساسية التحتية اللازمة لإنثاء الحدائق و المتنزهات في إطار التخطيط r. إن الإهتمام بالإحصاءات البيئة و إعداد قاعدة بيانات دقيقة يعد من المنطلبات الأساسية

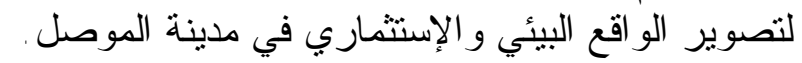

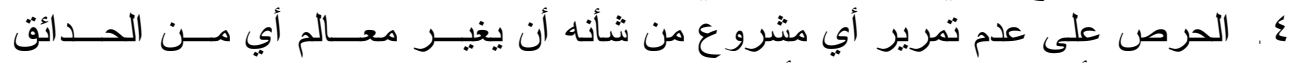
الموجودة أو يقتطع جز عأ منها أو يلغيها.

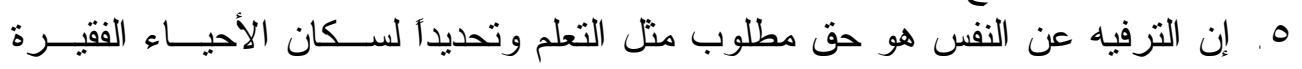

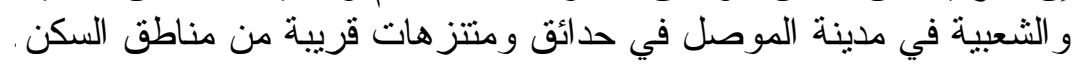

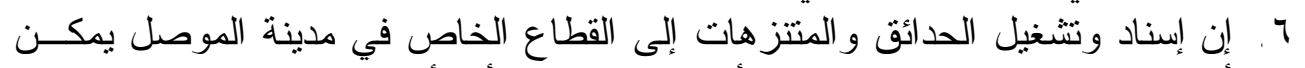

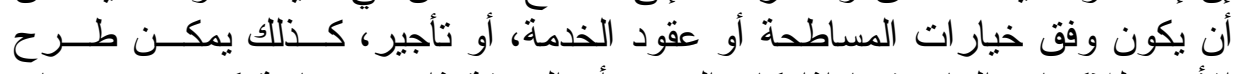

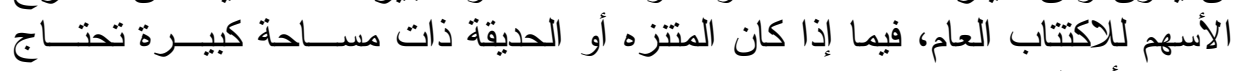

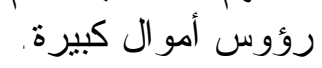

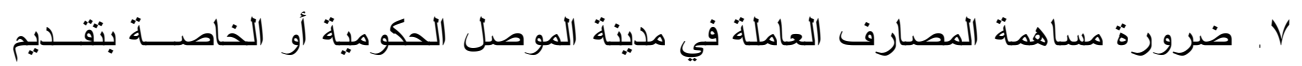

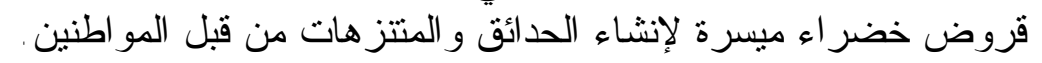

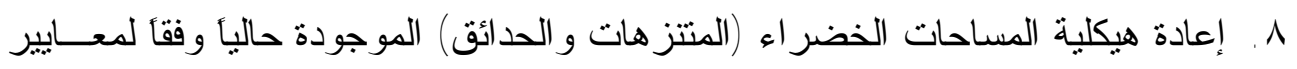

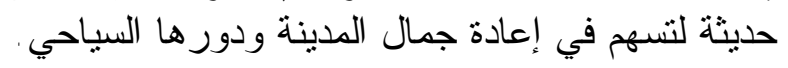

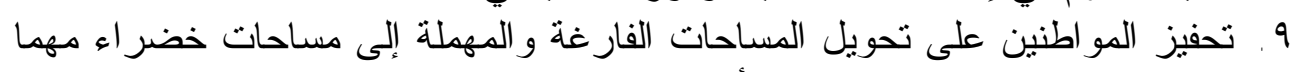

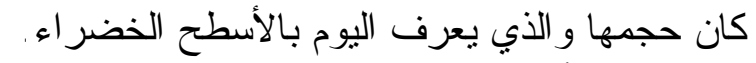
• 1 .نتكيل لجنة أصدقاء الحدائق و المتنز هات و المساهمة في متابعتها وتطوير هاء. 


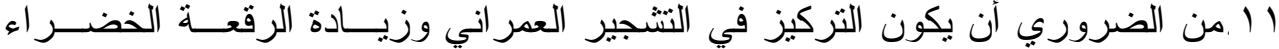

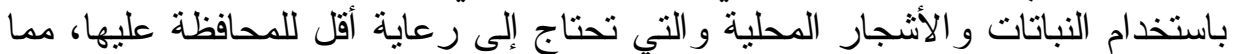

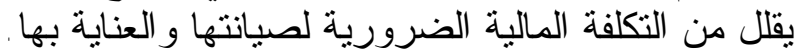

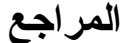

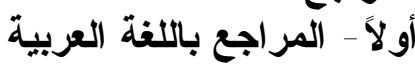

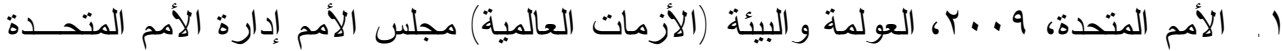

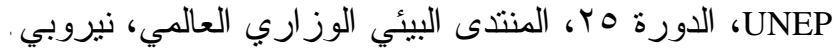

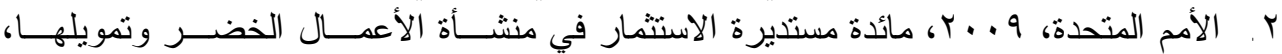

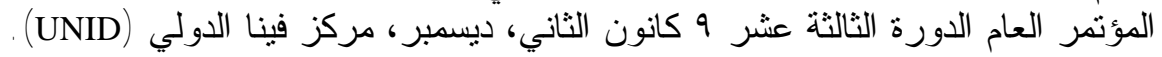

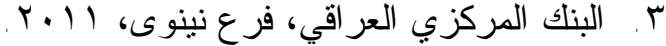

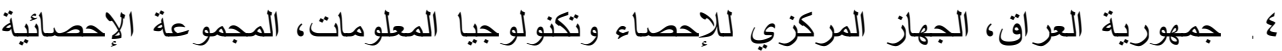

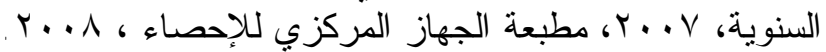

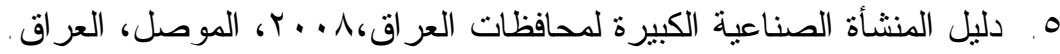

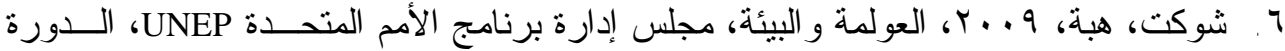

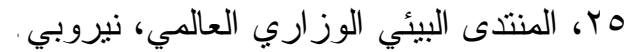

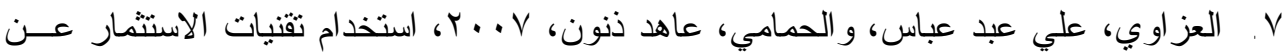

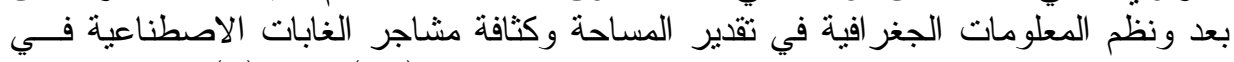

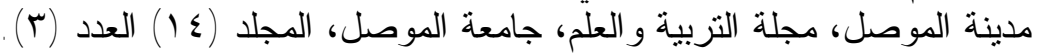

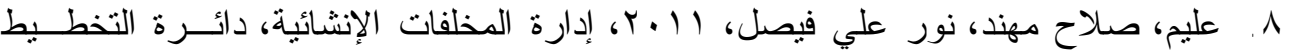

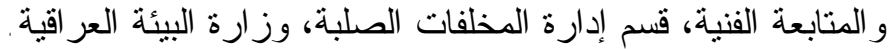

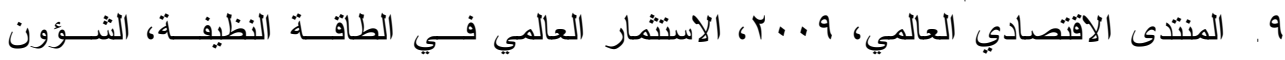

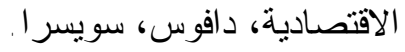

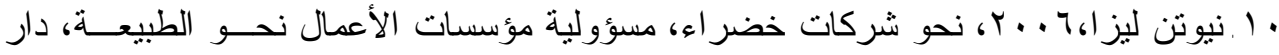

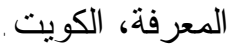

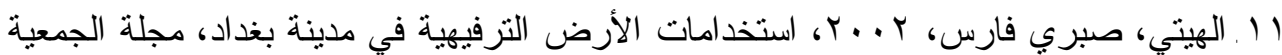

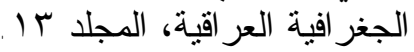

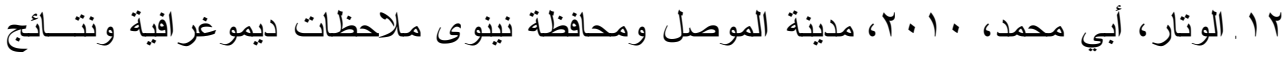

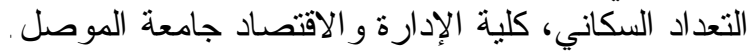

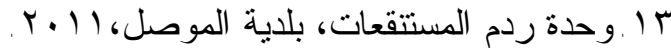

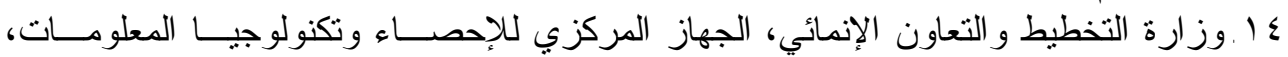

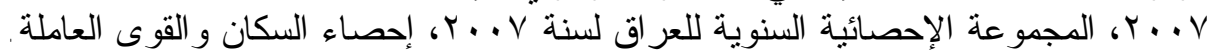

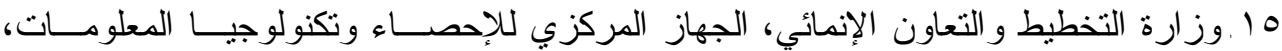

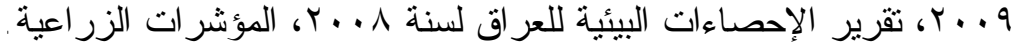

ثاتياً - المر اجع باللغة الأجنبية

1. Alwneh, Ziyad, 2007, Expert Group Meeting on Trade and Environment Priorities in the Arab Region, View of Civil Society: Engaging Civil Society on Trade and Environment . Issues, Grand Hayatt, Cairo.

2. Bismarck, Maxvon and Gurung, Anuadha, 2009, Green Investing, World Economic Forum, USA. 


\section{الشكر جي والشرابي والدليمي[^]}

3. Katherine Pease and Associate, 2008, Green Investment Strategy Report, New York Community Trust ,July.

4. Pollin Roberto, 2009, Economic Prospects New Labor Forum, U.S.A.

\section{ثالثاً - مواقع الاتترنت}

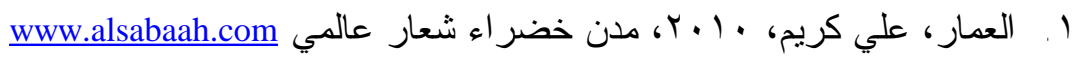

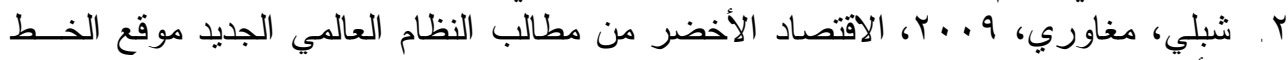

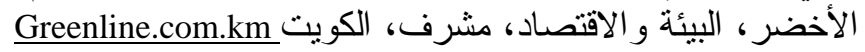

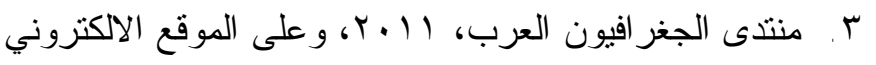
www.arbgeograbers.net/vb/showthread. 